\title{
On the effect of injection timing on the ignition of lean PRF/air/EGR mixtures under direct dual fuel stratification conditions
}

\author{
Minh Bau Luonga, Ramanan Sankaran ${ }^{\mathrm{b}}$, Gwang Hyeon Yu ${ }^{\mathrm{a}}$, Suk Ho Chung ${ }^{\mathrm{c}}$, \\ Chun Sang Yoo ${ }^{\mathrm{a}, *}$ \\ ${ }^{a}$ Department of Mechanical Engineering, Ulsan National Institute of Science and Technology, Ulsan 44919, Republic of Korea \\ ${ }^{\mathrm{b}}$ National Center for Computational Sciences, Oak Ridge National Laboratory, Oak Ridge, TN 37831, USA \\ ${ }^{c}$ Clean Combustion Research Center, King Abdullah University of Science and Technology, Thuwal, Saudi Arabia
}

\section{A R T I C L E I N F O}

\section{Article history:}

Received 8 February 2017

Revised 20 March 2017

Accepted 18 May 2017

\section{Keywords:}

Direct numerical simulation (DNS)

Homogeneous-charge compression ignition

( $\mathrm{HCCl})$

Direct dual fuel stratification (DDFS)

Reactivity controlled compression ignition

(RCCI)

Primary reference fuel (PRF)

\begin{abstract}
A B S T R A C T
The ignition characteristics of lean primary reference fuel (PRF)/air/exhaust gas recirculation (EGR) mixture under reactivity-controlled compression ignition (RCCI) and direct duel fuel stratification (DDFS) conditions are investigated by 2-D direct numerical simulations (DNSs) with a 116-species reduced chemistry of the PRF oxidation. The 2-D DNSs of the DDFS combustion are performed by varying the injection timing of iso-octane $\left(i-\mathrm{C}_{8} \mathrm{H}_{18}\right)$ with a pseudo-iso-octane $\left(\mathrm{PC}_{8} \mathrm{H}_{18}\right)$ model together with a novel compression heating model to account for the compression heating and expansion cooling effects of the piston motion in an engine cylinder. The $\mathrm{PC}_{8} \mathrm{H}_{18}$ model is newly developed to mimic the timing, duration, and cooling effects of the direct injection of $i-\mathrm{C}_{8} \mathrm{H}_{18}$ onto a premixed background charge of PRF/air/EGR mixture with composition inhomogeneities. It is found that the RCCI combustion exhibits a very high peak heat release rate (HRR) with a short combustion duration due to the predominance of the spontaneous ignition mode of combustion. However, the DDFS combustion has much lower peak HRR and longer combustion duration regardless of the fuel injection timing compared to those of the RCCI combustion, which is primarily attributed to the sequential injection of $i-\mathrm{C}_{8} \mathrm{H}_{18}$. It is also found that the ignition delay of the DDFS combustion features a non-monotonic behavior with increasing fuel-injection timing due to the different effect of fuel evaporation on the low-, intermediate-, and high-temperature chemistry of the PRF oxidation. The budget and Damköhler number analyses verify that although a mixed combustion mode of deflagration and spontaneous ignition exists during the early phase of the DDFS combustion, the spontaneous ignition becomes predominant during the main combustion, and hence, the spread-out of heat release rate in the DDFS combustion is mainly governed by the direct injection process of $i-\mathrm{C}_{8} \mathrm{H}_{18}$. Finally, a misfire is observed for the DDFS combustion when the direct injection of $i-\mathrm{C}_{8} \mathrm{H}_{18}$ occurs during the intermediate-temperature chemistry (ITC) regime between the first- and second-stage ignition. This is because the temperature drop induced by the direct injection of $i-\mathrm{C}_{8} \mathrm{H}_{18}$ impedes the main ITC reactions, and hence, the main combustion fails to occur.
\end{abstract}

(c) 2017 The Combustion Institute. Published by Elsevier Inc. All rights reserved.
This manuscript has been authored by UT-Battelle, LLC under Contract No. DE-AC05-00OR22725 with the U.S. Department of Energy. The United States Government retains and the publisher, by accepting the article for publication, acknowledges that the United States Government retains a non-exclusive, paid-up, irrevocable, worldwide license to publish or reproduce the published form of this manuscript, or allow others to do so, for United States Government purposes. The Department of Energy will provide public access to these results of federally sponsored research in accordance with the DOE Public Access Plan (http://energy.gov/ downloads/doe-public-access-plan).

* Corresponding author.

E-mail addresses: csyoo@unist.ac.kr, withspring@gmail.com (C.S. Yoo).

\section{Introduction}

A homogeneous-charge compression ignition ( $\mathrm{HCCI}$ ) engine has widely been investigated as one of the low-temperature combustion engines because it can provide better thermal efficiency and lower NOx and soot emissions than the conventional $\mathrm{CI}$ and SI engines [1-4]. Despite its promising advantages over the conventional IC engines, the development of its prototype has not been so successful because several critical problems still remain to be solved such as mitigating excessive pressure rise rate (PRR) and controlling ignition timing under high-load operation conditions. To overcome these difficulties, many modifications to HCCI engines have been made in the engine community [1-7]. 


$\begin{array}{ll}\text { Nomenclature } \\ \text { DNS } & \text { direct numerical simulation } \\ \text { PRF } & \text { primary reference fuel } \\ \text { EGR } & \text { exhaust gas recirculation } \\ \text { HCCI } & \text { homogeneous-charge compression ignition (HCCI) } \\ \text { RCCI } & \text { reactivity-controlled compression ignition } \\ \text { DDFS } & \text { direct duel fuel stratification } \\ \text { PPC } & \text { partially premixed combustion } \\ \text { GCI } & \text { gasoline compression ignition } \\ \text { HRR } & \text { heat release rate } \\ \text { LTC } & \text { low-temperature chemistry } \\ \text { ITC } & \text { intermediate-temperature chemistry } \\ \text { HTC } & \text { high-temperature chemistry } \\ \text { LTHR } & \text { low-temperature heat release } \\ { }^{\circ} \text { CA } & \text { degrees of crank angle } \\ \text { TDC } & \text { top dead center } \\ \text { BTDC } & \text { before the top dead center } \\ \text { ATDC } & \text { after the top dead center } \\ \text { IMEP } & \text { indicated mean effective pressure } \\ \text { RPM } & \text { revolutions per minute } \\ \text { PC }{ }_{8} \mathrm{H}_{18} & \text { pseudo-iso-octane } \\ t_{\text {inj }} & \text { injection timing } \\ t_{\text {dur }} & \text { injection duration } \\ \tau_{\text {ig }} & \text { ignition delay time }\end{array}$

Recently, reactivity-controlled compression ignition (RCCI) combustion has emerged as one of the most compelling alternatives to HCCI combustion because it exhibits a better controllability of the combustion process without sacrificing the benefits of HCCI combustion: high-thermal efficiency, improved fuel consumption, and ultra-low pollutant emissions [5-7]. For the RCCI combustion, two different fuels with opposite auto-ignition characteristics are supplied into the engine cylinder to control the combustion process. Low-reactivity fuel is first supplied through port injection to produce well-premixed charge of fuel and oxidizer, which is then followed by one or more direct injections of high-reactivity fuel to generate spatial inhomogeneities in reactivity and equivalence ratio of the charge. By adjusting the mass ratio of two fuels and the timing/duration of direct injection of high-reactivity fuel, we can achieve a fast-response control of the ignition timing and duration of the RCCI combustion [6,7].

Under high-load conditions, however, we cannot take full advantage of the RCCI combustion because it becomes more like an $\mathrm{HCCl}$ combustion. As the load increases, the RCCI ignition delay is prone to decrease. To compensate for this, the supply of directinjected high-reactivity fuel needs to be reduced and ultimately, it vanishes when the load becomes high enough. At this point, we may lose the control of the combustion phasing and process of the RCCI combustion. Moreover, since the port-injected low-reactivity fuel is usually well-premixed with oxidizer and hence, the overall combustion can occur by volumetric auto-ignition, similar to the HCCI combustion.

A remedy for extending the high-load limit of the RCCI combustion is to increase the resistance-to-autoignition quality of the lowreactivity fuel by replacing gasoline with much lower-reactivity fuel such as ethanol [8,9] and natural gas [10]. At high load, the high-reactivity fuel just serves as an ignition source to initiate the start of combustion while most of the heat release comes from low-reactivity fuel. As such, this method can offer a robust control of the combustion phasing with good combustion stability $[11,12]$.

Another approach for expanding the operation range to a higher load and avoiding excessive premixing of the charge of the $\mathrm{RCCl}$ combustion is to stratify both fuels by directly injecting gasoline and diesel into the engine cylinder [12-16]. This method allows more flexible controllability of the in-cylinder reactivity distribution of the two fuels. Kavuri et al. elucidated the characteristics of the RCCI combustion using direct injection of both gasoline and diesel fuels at high load and compared its performance with gasoline compression ignition (GCI) combustion [16]. They found that both RCCI and GCI combustion have similar overall combustion characteristics with a near top dead center (TDC) injection; however, the RCCI combustion has better control of the combustion phasing than GCI combustion. Lim et al. studied numerically the RCCI combustion with dual direct injections of iso-octane and $n$ heptane under high-load conditions [12]. They showed that the RCCI combustion can achieve very-high gross thermal efficiency of $48.7 \%$ with 21 bar gross indicated mean effective pressure (IMEP) by an optimal injection strategy compared to $47 \sim 48 \%$ efficiency with up to 16 bar gross IMEP in a boosted HCCI engine using E10 fuel (a 10\% ethanol and 90\% gasoline blend) [17].

More recently, Wissink and Reitz demonstrated that compared to the RCCI combustion, direct dual fuel stratification (DDFS) combustion is more effective in distributing HRR and reducing PRR at high-load conditions [13-15]. The DDFS combustion combines the high thermal efficiency of the RCCI combustion with the high load capability of partially premixed combustion (PPC) while reducing exhaust gas recirculation (EGR) rate, noise, and combustion instabilities. In the DDFS combustion, the start of the heat release is controlled by the direct injection of diesel while the peak and duration of the heat release are governed by near-TDC gasoline injection. Similar to the RCCI combustion, in particular, the DDFS combustion utilizes an early injection of gasoline to form premixed background charge, followed by direct injection of diesel to generate some degrees of reactivity and equivalence ratio stratification. These two injections are designed to control the start of the main combustion occurring at about $-10^{\circ} \mathrm{CA}$ after the TDC (ATDC). Inspired by the PPC, the DDFS combustion utilizes high-pressure direct injection of gasoline right before the TDC (BTDC). As such, DDFS combustion can achieve a capability to independently control ignition timing and combustion duration by combining reactivity stratification with diffusion-limited gasoline injection [13-15]. However, the effect of the timing of the late gasoline injection on the combustion process of both fuel stratification is not well-understood.

In previous direct numerical simulation (DNS) studies, the ignition characteristics of HCCI [18-28], SCCI [29-34], and RCCI $[35,36]$ combustion have been investigated at constant volume. In real IC engines, however, the combustion process is highly affected by both the compression heating before TDC and the expansion cooling after the TDC by the piston motion. Moreover, two-stage ignition fuels such as diesel, primary reference fuel (PRF), and dimethyl ether (DME) exhibit a significant amount of radical buildup resulting from low-temperature heat release (LTHR) during the compression stroke at temperature below about $850 \mathrm{~K}$ [4]. The LTHR from the first-stage ignition can increase in-cylinder temperature by about $10-20 \mathrm{~K}$, which can cause the main combustion to occur earlier. Recently, the effects of compression heating and expansion cooling were considered in several DNS studies by adopting compression heating models [37-40].

In previous DNS studies of HCCI combustion, it was assumed that all of the multiple injections are finished to save computational cost. With the assumption, DNSs were then set up with appropriate initial fields with equivalence ratio and/or concentration inhomogeneities to account for the degree of in-cylinder stratification in fuel/air mixture induced by direct injections. Different degrees of initial fuel/air mixture inhomogeneities were imposed to account for variations in the timing/duration of late direct injections. Based on this approach, Zhang et al. numerically investigated 
the effect of split fuel injection on HRR and pollutant emissions of PRF70/air/EGR mixtures in a PPC engine [40]. The initial fields were initialized by assuming that the first/second injection forms a slight/high fuel inhomogeneity. 2-D DNSs started with such initial fields after the end of the second fuel injection, $10^{\circ} \mathrm{CA} \mathrm{BTDC}$ [40]. A similar technique was used in a multi-zone based study for RCCI combustion [41]. For multiple injection strategies, however, the previous approach is not capable of reproducing the timing and duration of a late direct injection, especially for cases in which the remaining fuel may be injected into an undergoing reacting charge as in [13-15].

Therefore, the objective of the present study is two-fold: (i) to develop a pseudo-iso-octane model to mimic the timing and duration of the late direct injection, and (ii) to investigate the effect of the late-direct-injection timing on the combustion process of $n$-heptane/iso-octane/air mixture with inhomogeneities in both fuels using 2-D DNSs. The effect of the compression heating and expansion cooling by the piston motion is also taken into account by adopting a novel compression heating model. Note that DNSs of the ignition of hydrocarbon/air mixtures with composition inhomogenities under high pressure conditions, which incorporate some practical models such as the compression heating and fuel injection models, can provide unprecedented data sets to understand its fundamental combustion characteristics and to ultimately develop and validate novel turbulence and combustion models.

\section{Model development}

\subsection{Compression heating model}

The reciprocating motion of the piston causes compression heating and expansion cooling of the charge within the engine cylinder. As such, it is of importance to capture the effects of the compression heating before the TDC on the unburned mixture because the pressure and temperature rise during the induction period can have a significant influence on the low-temperature chemistry and radical accumulation. Likewise, the temperature drop due to expansion cooling should also be considered because it has a profound effect on the accurate prediction of incomplete combustion and formation of unburned hydrocarbons. While the fixed mesh flow solver used in the present study allows for a high order of numerical accuracy, it does not provide a straightforward way to account for the effects of moving boundaries such as the piston motion.

There have been several studies [37-39,42,43] in which the effects of pressure change were incorporated through the use of additional source terms in the governing equations instead of moving the meshes or varying the volume of the computational domain. Following this approach, we add additional source terms to the governing equations. These terms inject/remove mass, momentum, and energy to mimic the effects of compression and expansion. Our formulation for the source terms ensures that the thermodynamic pressure of the system is varied without introducing any variations in the local hydrodynamic pressure, as the latter would unphysically affect the development of the turbulent flow. More specifically, the compression heating model in [39] was adopted not only to account for volume change due to the piston motion but also to match an experimental pressure trace of a fired engine. As such, the thermodynamic pressure in their DNSs [39] followed the imposed pressure trace. In the present study, however, the compression heating model is used only to reproduce a motored pressure trace of an experimental engine and hence, the pressure rise due to combustion is allowed to evolve on its own. The formulation of the mass source terms is similar to that presented in [39] but it is repeated here for convenience.
The chamber volume of an internal combustion engine can be determined using the slider-crank relation [44]. Based on that, close to the TDC, the motored pressure trace can be approximated by:

$P_{\mathrm{m}}(t)=P_{0, \mathrm{~m}}\left[1+g^{2} \pi^{2} \frac{\left(t-t_{0}\right)^{2}}{t_{c}^{2}}\right]^{-n}$,

where $P_{0, m}$ is the motored TDC pressure, $t_{c}$ is the time taken for one crank rotation, $t_{0}$ is the time at the TDC and $g$ is a model factor to account for the crank slider geometry. The experimental pressure trace from Wissink et al. [13] is used to calibrate the geometry factor in Eq. (1) and obtain the analytical expression for the motored pressure trace.

To include the effects of the pressure change due to the piston motion, the DNS governing equations need to be modified with appropriate mass source term, along with the corresponding momentum and energy source terms. The fully compressible NavierStokes equations: continuity, momentum, total energy, and species continuity equations are solved in conservative form with detailed chemistry,

$$
\begin{aligned}
\frac{\partial \rho}{\partial t} & =-\frac{\partial \rho u_{i}}{\partial x_{i}}+\dot{m} \\
\frac{\partial \rho u_{i}}{\partial t} & =-\frac{\partial \rho u_{i} u_{j}}{\partial x_{j}}-\frac{\partial P}{\partial x_{i}}+\frac{\partial \tau_{i j}}{\partial x_{j}}+\dot{m} u_{\mathrm{i}} \\
\frac{\partial \rho e_{t}}{\partial t} & =-\frac{\partial \rho e_{t} u_{j}}{\partial x_{j}}-\frac{\partial P u_{j}}{\partial x_{j}}+\frac{\partial\left(\tau_{i j} \cdot u_{i}\right)}{\partial x_{j}}-\frac{\partial q_{j}}{\partial x_{j}}+\dot{m} e_{t} \\
\frac{\partial \rho Y_{k}}{\partial t} & =-\frac{\partial \rho Y_{k} u_{j}}{\partial x_{j}}-\frac{\partial J_{k, j}}{\partial x_{j}}+\omega_{k}+\dot{m} Y_{k}
\end{aligned}
$$

where $\rho$ is the density, $u_{i}$ are the Cartesian velocity components, $P$ is pressure, $Y_{k}$ is the species mass fraction of the $k$-th species and $\omega_{k}$ is its reaction rate, $\tau_{i j}$ is the viscous stress tensor given by $\tau_{i j}=\mu\left(\frac{\partial u_{i}}{\partial x_{j}}+\frac{\partial u_{j}}{\partial x_{i}}-\frac{2}{3} \delta_{i j} \frac{\partial u_{l}}{\partial x_{l}}\right)$. The total specific energy is given by $e_{t}=u_{i} u_{i} / 2+h-P / \rho$ and the heat flux vector is given by $q_{i}=$ $-\lambda \frac{\partial T}{\partial x_{i}}+\Sigma_{k} h_{k} J_{k, i}$. The species diffusive flux is computed through a mixture averaged formulation based on a form of Fick's law, $J_{k, i}=$ $-\rho D_{k} \frac{\partial Y_{k}}{\partial x_{i}}-\frac{\rho D_{k} Y_{k}}{M} \frac{\partial M}{\partial x_{i}}$ where $M$ is the mixture-averaged molecular weight and $D_{k}$ is a mixture-averaged diffusion coefficient $[45,46]$. Nitrogen is used as the bath gas, i.e. the diffusion flux of nitrogen balances the sum of the diffusion fluxes for the other species in order to ensure that the net diffusion flux is zero.

The ideal gas equation of state is used such that

$P(\mathbf{x}, t)=P_{\mathrm{t}}(t)+p(\mathbf{x}, t)=\rho R T$,

where $P_{\mathrm{t}}=\bar{P}$ is the thermodynamic pressure of the domain, $p$ is the local hydrodynamic pressure and $R$ is the specific gas constant. The thermodynamic pressure change due to the piston motion, $d P_{\mathrm{m}} / d t$, is obtained by differentiating Eq. (1) with respect to time. The local mass source term that needs to be added is then given by:

$\dot{m}=\frac{\rho}{P} \frac{d P_{\mathrm{m}}}{d t}$.

The compression heating model adopted in the present study has an improved feature compared to those used in the previous studies $[37,38,42,43]$. The previous models used a mass source term which is uniform across all grid points regardless of the presence of temperature and equivalence ratio inhomogeneities. Such a uniform mass source term may induce pressure disturbance in the domain. The mass source term in the present model is, therefore, not uniform across the domain, but rather depends on local density as seen from the relation of Eq. (4). As such, the thermodynamic pressure varies uniformly across the domain to ensure that 


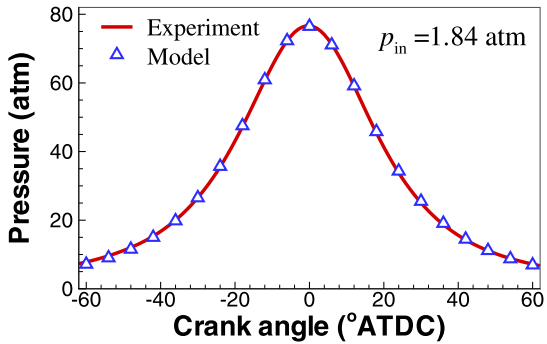

Fig. 1. Experimental and modeled motored-pressure history as a function of crank angle degrees $\left({ }^{\circ} \mathrm{CA}\right)$. Experimental motored-pressure trace is taken from experiment by Wissink and Reitz [13] operating at $1300 \mathrm{RPM}$ and $p_{\text {in }}=1.84 \mathrm{~atm}$.

Table 1

Engine specifications [13] and key parameters of the DNS cases. RPM, 'CA ATDC, and EGR denote revolutions per minute, degrees of crank-angle after the top dead center, and exhaust gas recirculation, respectively.

\begin{tabular}{ll}
\hline Relevant engine parameters & \\
\hline Ratio of connecting-rod length to crank radius & 3.17 \\
Compression ratio & $14.88: 1$ \\
Intake pressure & $1.84(\mathrm{~atm})$ \\
Engine speed & $1300(\mathrm{RPM})$ \\
\hline Parameters at initial conditions & \\
\hline Initial crack angle & $-25\left({ }^{\circ} \mathrm{CA}\right.$ ATDC) \\
Initial mean temperature, $T_{0}$ & $735(\mathrm{~K})$ \\
Initial temperature fluctuation, $T^{\prime}$ & $20(\mathrm{~K})$ \\
Initial mean pressure, $P_{0}$ & $35(\mathrm{~atm})$ \\
EGR mass fraction & $40 \%$ \\
EGR compositions (in mass fraction) & $19 \% \mathrm{CO}, 8 \% \mathrm{H}_{2} \mathrm{O}$, and $73 \% \mathrm{~N}_{2}$ \\
\hline RCCI & \\
\hline Initial mean equivalence ratio, $\phi_{0}$ & 0.60 \\
Initial mean PRF number, PRF & PRF70 \\
\hline DDFS & \\
\hline Initial mean equivalence ratio before injection & 0.41 \\
Initial mean PRF number before injection & PRF55 \\
Mean equivalence ratio after injection & 0.60 \\
Mean PRF number after injection & PRF70 \\
Sweep of injection timing, $t_{\text {inj }}$ & -25 to $2.3\left({ }^{\circ} \mathrm{CA}\right.$ ATDC) \\
Effective injection duration, $t_{\text {dur }}$ & $0.8(\mathrm{~ms})$ \\
\hline
\end{tabular}

the original hydrodynamics pressure distribution is retained, and no steep thermodynamic pressure gradients are created. Figure 1 shows the modeled motored-pressure trace that perfectly matches the experimental one without any noticeable discrepancies in the time duration of interest considered in the present study. The relevant engine parameters taken from [13] are listed in Table 1 with the compression ratio, intake pressure, and engine speed of 14.88 , $1.84 \mathrm{~atm}$, and $1300 \mathrm{rpm}$, respectively.

\subsection{Pseudo-iso-octane model}

In this section, the development of a pseudo-iso-octane (denoted as $\mathrm{PC}_{8} \mathrm{H}_{18}$ ) model capable of resembling multiple direct injections is discussed. The $\mathrm{PC}_{8} \mathrm{H}_{18}$ model is then used to study the influence of late injection of iso-octane on the ignition characteristics of PRF/air/EGR mixture under DDFS conditions.

As in the DDFS combustion [13-15], the initial mixture field is primarily composed of a uniform iso-octane/air mixture representative of a well-mixed charge resulting from very early gasoline injection. A stratified $n$-heptane composition is then superimposed to mimic the second injection, which corresponds to the direct injection of diesel fuel. The injection of the diesel fuel occurs prior to the TDC with insufficient time for complete mixing. Therefore, the composition inhomogeneities of the diesel fuel is to be expected. In addition, there is very little reactivity and heat release during the diesel injection event, which allows the diesel stratifica-

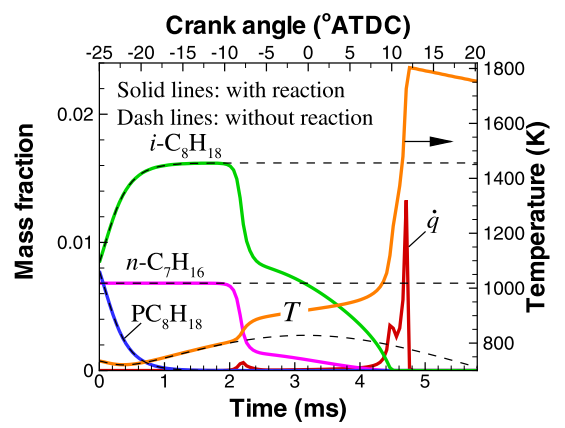

Fig. 2. Temporal evolutions of the mass fraction of $i-\mathrm{C}_{8} \mathrm{H}_{18}, \mathrm{PC}_{8} \mathrm{H}_{18}$, and $n-\mathrm{C}_{7} \mathrm{H}_{16}$, temperature, and heat release rate of the 0 -D ignition for Case 3 with and without reaction. The initial pressure, temperature, and $t_{\text {inj }}$ are $35 \mathrm{~atm}, 735 \mathrm{~K}$, and $-25^{\circ} \mathrm{CA}$ ATDC, respectively. The effective injection duration, $t_{\mathrm{dur}}$, is approximately $0.8 \mathrm{~ms}$.

tion to be represented through the initial condition. The last injection event is the gasoline direct injection close to the TDC, during which combustion and heat release have already commenced. Injecting nascent fuel into the system in the presence of significant heat release is especially challenging in a direct numerical simulation. This can lead to strong pressure variations and scalar gradients that cannot be handled by the dissipation free numerical methods used in the present study.

In this section, we develop the $\mathrm{PC}_{8} \mathrm{H}_{18}$ model to simulate the effects of the late injection of gasoline with a two-step process. As a part of the initial condition, stratified iso-octane composition is added to the mixture field, using a pseudo-iso-octane molecule . The chemical species, $\mathrm{PC}_{8} \mathrm{H}_{18}$, that forms a stratified mixture field is non-reactive during the initial phases of the simulation. Once the simulation has advanced close to the TDC, the $\mathrm{PC}_{8} \mathrm{H}_{18}$ species is converted to the usual reactive iso-octane species, $i-\mathrm{C}_{8} \mathrm{H}_{18}$. This introduces reactive iso-octane in the system at the appropriate juncture when gasoline injection is needed. The consumption of $\mathrm{PC}_{8} \mathrm{H}_{18}$ and its conversion to reactive $i-\mathrm{C}_{8} \mathrm{H}_{18}$ occurs through a source term, which resembles a Gaussian function in time. The form of the Gaussian conversion function is chosen to achieve the desired timing and duration, $t_{\text {inj }}$ and $t_{\mathrm{dur}}$, of gasoline injection. This conversion step allows the effects of gasoline injection during active combustion to be simulated without numerical instability issues. While all the thermochemical and transport properties of the $\mathrm{PC}_{8} \mathrm{H}_{18}$ are chosen to identically match those of $i-\mathrm{C}_{8} \mathrm{H}_{18}$, the enthalpy of formation of $\mathrm{PC}_{8} \mathrm{H}_{18}$ is chosen to be lower than $i-\mathrm{C}_{8} \mathrm{H}_{18}$. This difference in the enthalpy of formation causes a drop in temperature, thereby allowing the simulations to also account for the temperature drop due to the latent heat of evaporation of direct gasoline fuel injection.

In summary, the underlying idea behind the $\mathrm{PC}_{8} \mathrm{H}_{18}$ model is that at the beginning, $\mathrm{PC}_{8} \mathrm{H}_{18}$ is initialized with other fuels $(n$ heptane + iso-octane), and acts as an inert gas. At a specific time, so-called $t_{\text {inj }}, \mathrm{PC}_{8} \mathrm{H}_{18}$ is gradually converted to real iso-octane for a given time duration of $t_{\text {dur }}$ to participate in the combustion process. The process of converting $\mathrm{PC}_{8} \mathrm{H}_{18}$ to $i-\mathrm{C}_{8} \mathrm{H}_{18}$ is representative of the late direct injection of gasoline [13]. For illustration, Fig. 2 shows that $\mathrm{PC}_{8} \mathrm{H}_{18}$ starts to be converted to $i-\mathrm{C}_{8} \mathrm{H}_{18}$ via the Gaussian function at $t_{\text {inj }}$ of $-25^{\circ} \mathrm{CA}$ ATDC. The effective injection duration or the conversion time of $\mathrm{PC}_{8} \mathrm{H}_{18}$ to $i-\mathrm{C}_{8} \mathrm{H}_{18}, t_{\mathrm{dur}}$, of $0.8 \mathrm{~ms}$ is chosen as in [13] for all the DDFS cases in the present study.

\section{Numerical methods and initial conditions}

The Sandia DNS code, S3D, is used to solve the fully compressible governing equations in Eq. (2) [46]. A fourth-order explicit Runge-Kutta method [47] for time integration and an eighthorder central differencing scheme for spatial discretization [48] are adopted. A tenth-order filter is also applied to remove any spuri- 
Table 2

Mean mole, $\bar{x}$, of $n-\mathrm{C}_{7} \mathrm{H}_{16}, \mathrm{PC}_{8} \mathrm{H}_{18}$, and $i-\mathrm{C}_{8} \mathrm{H}_{18}$ in RCCI and DDFS cases. Both $n-\mathrm{C}_{7} \mathrm{H}_{16}$ and $\mathrm{PC}_{8} \mathrm{H}_{18}$ fields are initialized by $x=\bar{x}+x^{\prime}$, where $\bar{x}$ of 0.324 , and $x^{\prime}$ of 0.1 represent the mean value and variance, respectively.

\begin{tabular}{llll}
\hline Composition & RCCI & DDFS & Distribution \\
\hline$n-\mathrm{C}_{7} \mathrm{H}_{16}$ & 0.324 & 0.324 & Inhomogeneous \\
$\mathrm{PC}_{8} \mathrm{H}_{18}$ & - & 0.324 & Inhomogeneous \\
$i-\mathrm{C}_{8} \mathrm{H}_{18}$ & 0.676 & 0.352 & Homogeneous \\
$\mathrm{PRF}_{0}$ & PRF70 & PRF70 & \\
\hline
\end{tabular}

ous high-wavenumber fluctuations in the solution. CHEMKIN and TRANSPORT software libraries [49,50] are linked with S3D to calculate reaction rates and thermodynamic and mixture-averaged transport properties. Periodic boundary conditions are imposed in all directions of the fixed computational domain. For details of the numerical methods, readers are referred to [46].

A 116-species reduced mechanism for PRF oxidation [23] is adopted to simulate the RCCI/DDFS combustion [13]. PRF is a mixture of $n$-heptane and iso-octane, which have widely been used as a realistic surrogate for high- and low-reactivity fuels, diesel and gasoline, respectively. The reduced mechanism was developed from the LLNL detailed chemistry with 874 species and 3796 elementary reactions for DNSs of HCCI combustion [51,52]. The reduced mechanism was validated under a wide range of PRF composition, pressure, and temperature conditions. Details of the reduced and skeletal mechanisms for PRF oxidation can be found in [23]. The stiffness removal technique was adopted to remove any chemical timescales shorter than $10 \mathrm{~ns}$ [53]. $\mathrm{PC}_{8} \mathrm{H}_{18}$ is incorporated into the 116-species mechanism [23], forming a 117-species mechanism. Note that except the difference in the number of species, the 117species mechanism has the same features as the 116-species mechanism because $\mathrm{PC}_{8} \mathrm{H}_{18}$ is a non-reactive species and just acts as an inert gas. Note that for RANS-based engine simulations, several compact-size reduced PRF mechanisms such as 32 species with 55 reactions [54], 41 species with 130 reactions [55], and 73 species with 296 reactions reduced mechanisms [56] have been developed considering a trade-off between the computational efficiency and the mechanism accuracy.

The relevant engine specifications and the physical and numerical parameters for DNSs are summarized in Tables 1-3. To save computational cost, all the simulations (Cases 1-8) start at $-25^{\circ} \mathrm{CA}$ ATDC, at which the injection of $n$-heptane is assumed to be already finished. Based on the motored pressure trace with an intake pressure of $1.84 \mathrm{~atm}$ as shown in Fig. 1, the mean pressure, $P_{0}$, at $-25^{\circ} \mathrm{CA}$ ATDC is set to be $35 \mathrm{~atm}$. The initial mean temperature, $T_{0}$ of $735 \mathrm{~K}$, mean equivalence ratio, $\phi_{0}$ of 0.60 , and mean fuel, $\mathrm{PRF}_{0}$ of PRF70, are chosen for all DNSs except for Case 1 with $\phi_{0}$ of 0.41 and $\mathrm{PRF}_{0}$ of PRF55. Note that in Case 1, the conversion process of $\mathrm{PC}_{8} \mathrm{H}_{18}$ to $i-\mathrm{C}_{8} \mathrm{H}_{18}$ does not occur, and hence, its overall

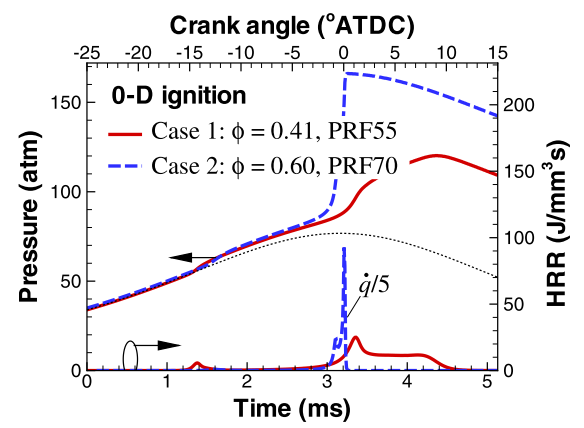

Fig. 3. Temporal evolutions of the pressure and the HRR of the $0-D$ ignition for Cases 1 and 2 with the initial pressure of $35 \mathrm{~atm}$ and temperature of $735 \mathrm{~K}$. The dot line represents the modeled motored-pressure trace.

equivalence ratio is much lower than those of the other cases. To reduce excessive HRR, EGR is added to the initial PRF/air mixture. In the present study, the composition of EGR is assumed to be the complete combustion products of stoichiometric PRF70/air mixture [37], which composes of $19 \% \mathrm{CO}_{2}, 8 \% \mathrm{H}_{2} \mathrm{O}$, and $73 \% \mathrm{~N}_{2}$ by mass. The EGR ratio is defined as the mass fraction of EGR in the fuel/air/EGR mixture. As in [13], a dilution level of $40 \%$ mass fraction of EGR is used for all cases. The temperature of EGR is assumed to be the same as that of the reactants.

Six DDFS cases (Cases 3-8 in Table 3 ) are simulated by varying the injection timing of the late iso-octane direct injection, $t_{\mathrm{inj}}$, ranging from -25 to $2.3^{\circ} \mathrm{CA}$ ATDC. For the DDFS cases, both $\mathrm{PC}_{8} \mathrm{H}_{18}$ and $n$-heptane are initialized so that they are inhomogeneously superimposed onto a uniform $i-\mathrm{C}_{8} \mathrm{H}_{18} /($ air $+\mathrm{EGR}$ ) field (see Table 2). More specifically, both $n-\mathrm{C}_{7} \mathrm{H}_{16}$ and $\mathrm{PC}_{8} \mathrm{H}_{18}$ fields are initialized by $x=\bar{x}+x^{\prime}$, where $x$ denotes mole of either $n-\mathrm{C}_{7} \mathrm{H}_{16}$ or $\mathrm{PC}_{8} \mathrm{H}_{18}$, and $\bar{x}$ of 0.324 , and $x^{\prime}$ of 0.1 represent the mean value and variance, respectively. At a given time, $t_{\mathrm{inj}}$, during the simulation, $\mathrm{PC}_{8} \mathrm{H}_{18}$ is gradually converted into $i-\mathrm{C}_{8} \mathrm{H}_{18}$ to account for the late injection process of $i-\mathrm{C}_{8} \mathrm{H}_{18}$. Note that the DNSs of Cases 3-8 are restarted from Case 1 at each $t_{\text {inj }}$ to reduce the computational cost and minimize the effects of different initial scalar and turbulence fields.

To make a direct comparison between the DDFS and RCCI combustion, a representative case of RCCI combustion (Case 2) is simulated. Unlike the DDFS cases with both $n$-heptane and $i-\mathrm{C}_{8} \mathrm{H}_{18}$ fluctuations (Cases 3-7), only $n$-heptane concentration fluctuation is generated for Case 2. As listed in Table 2, $n-\mathrm{C}_{7} \mathrm{H}_{16}$ field is initialized by $x=\bar{x}+x^{\prime}$, superimposed onto a uniform $i-\mathrm{C}_{8} \mathrm{H}_{18} /($ air + EGR) field. Due to the inhomogeneities in the $n$-heptane field, the fluctuation in the reactivity (PRF) and equivalence ratio can be attained.

Figure 3 shows the temporal evolutions of the pressure and HRR for 0-D ignition of Case 1 (PRF55, $\phi_{0}=0.41$ ), and Case 2

Table 3

Physical parameters of the eight 2-D DNS cases. For all 2-D DNS cases, $l_{e}=l_{T e}=l_{n-C 7 H 16 e}$ $=l_{\mathrm{P} 8 \mathrm{H} 18 \mathrm{e}}=1.2 \mathrm{~mm}, u^{\prime}=0.4 \mathrm{~m} / \mathrm{s}$, and $\tau_{t}=3.0 \mathrm{~m} / \mathrm{s}$. Note that Case 1 is a baseline (BL) case in which $\mathrm{PC}_{8} \mathrm{H}_{18}$ is not converted into $i-\mathrm{C}_{8} \mathrm{H}_{18} . t_{\text {inj }}$ and $\tau_{\mathrm{ig}}^{0}$ denote the injection timing and the 0-D ignition delay time, respectively. $\tau_{\text {ig }}$ represents the time at which the maximum mean HRR occurs for both $0-\mathrm{D}$ and 2-D simulations and the superscript 0 denotes $0-\mathrm{D}$ simulation. Case 8 has no $\tau_{\mathrm{ig}}^{0}$ due to misfire.

\begin{tabular}{|c|c|c|c|c|c|c|c|c|}
\hline Case & Type & $\begin{array}{l}t_{\text {inj }} \\
\left(\mathrm{ms} \text { or }{ }^{\circ} \mathrm{CA} \text { ATDC) }\right.\end{array}$ & $\phi_{0}$ & $\mathrm{PRF}_{0}$ & $\phi^{\prime}$ & $\mathrm{PRF}^{\prime}$ & $\begin{array}{l}T^{\prime} \\
(\mathrm{K})\end{array}$ & $\begin{array}{l}\tau_{\mathrm{ig}}^{0} \\
(\mathrm{~ms})\end{array}$ \\
\hline 1 & $\mathrm{BL}$ & - & 0.41 & 55 & 0.07 & 9.7 & 20 & 3.4 \\
\hline 2 & RCCI & - & 0.60 & 70 & 0.07 & 7.7 & 20 & 3.2 \\
\hline 3 & DDFS & $0.0(-25.0)$ & 0.60 & 70 & 0.10 & 8.3 & 20 & 4.7 \\
\hline 4 & DDFS & $1.0(-17.2)$ & 0.60 & 70 & 0.10 & 8.3 & 20 & 3.6 \\
\hline 5 & DDFS & $2.5(-5.5)$ & 0.60 & 70 & 0.10 & 8.3 & 20 & 3.5 \\
\hline 6 & DDFS & $3.0(-1.6)$ & 0.60 & 70 & 0.10 & 8.3 & 20 & 3.6 \\
\hline 7 & DDFS & $3.5(+2.3)$ & 0.60 & 70 & 0.10 & 8.3 & 20 & 3.8 \\
\hline 8 & DDFS & $2.0(-9.4)$ & 0.60 & 70 & 0.10 & 8.3 & 20 & - \\
\hline
\end{tabular}



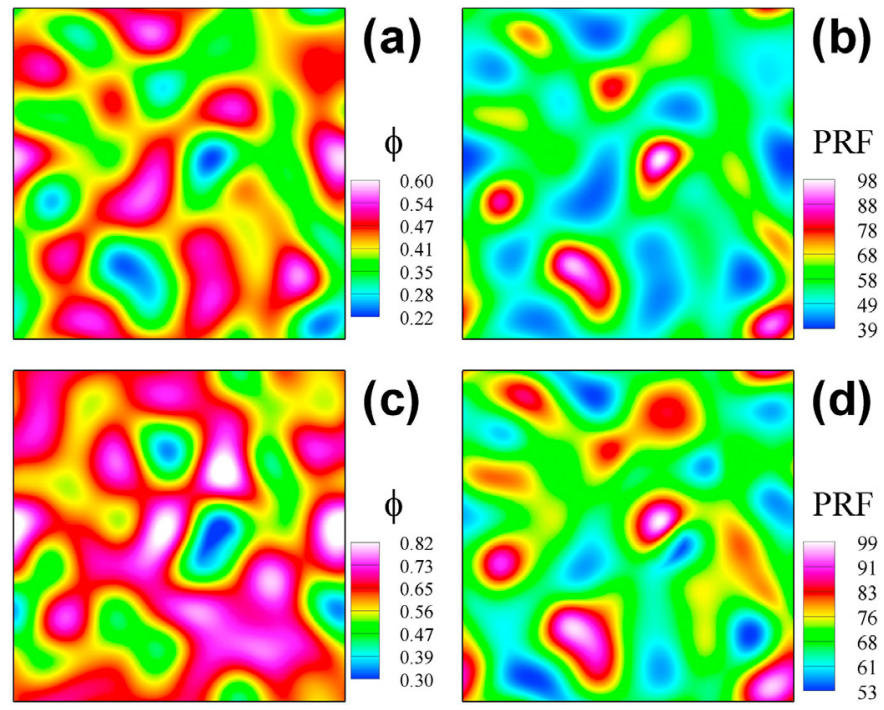

Fig. 4. Initial $\phi$ and PRF fields for $n-\mathrm{C}_{7} \mathrm{H}_{16}$ inhomogeneities only before the injection of $i-\mathrm{C}_{8} \mathrm{H}_{18}$ (top) and both $n-\mathrm{C}_{7} \mathrm{H}_{16}$ and $\mathrm{PC}_{8} \mathrm{H}_{18}$ inhomogeneities after the injection of $i-\mathrm{C}_{8} \mathrm{H}_{18}$ (bottom).

(PRF70, $\phi_{0}=0.60$ ). The corresponding 0-D ignition delays of Cases $1 \& 2$ are approximately 3.4 and $3.2 \mathrm{~ms}$, respectively. Henceforth, $\tau_{\text {ig }}$ represents the time at which the maximum mean HRR occurs for both $0-\mathrm{D}$ and 2-D simulations and the superscript 0 denotes 0 -D simulation. Based on the first-stage ignition delay time, $\tau_{\mathrm{ig}, 1}^{0}$, of Case 1, the injection timing of $i-\mathrm{C}_{8} \mathrm{H}_{18}$ is chosen such that for Cases 3-4, it occurs prior to the beginning of the first-stage ignition, while for Cases $5-8$, the injection of $i-\mathrm{C}_{8} \mathrm{H}_{18}$ occurs after the end of the first-stage ignition.

As in $[19,21,26,28-30,35,43,57-60]$, the initial turbulent flow field is prescribed by an isotropic kinetic energy spectrum function of Passot and Pouquet [61]. Initial fuel concentration and temperature fields are also generated by the same energy spectrum with different random numbers. For all DNSs, the most energetic length scale, $l_{e}$, of $1.2 \mathrm{~mm}$ is chosen. The characteristic length scale of the concentration and temperature fields is selected identical to $l_{e}$. Turbulence intensity, $u^{\prime}$, of 0.4 is deliberately selected to ensure that the turbulence time scale, $\tau_{t}=l_{e} / u^{\prime}=3.0 \mathrm{~ms}$, is equivalent to $\tau_{\mathrm{ig}}^{0}$ in a real $\mathrm{HCCl}$ engine. Due to the identical characteristic length scales and comparable time scales for turbulence and scalar fields, most effective turbulent mixing of the initial mixture can be expected in the present study $[20,22]$. The representative isocontours of initial fields of $\phi$ and PRF are shown in Fig. 4 for Cases 3-8.

Wang and Rutland [62] found that at the end of the evaporation process, (i) the difference in temperature field is approximately $100 \mathrm{~K}$, (ii) $\phi$ distribution is within a range of $0.1-0.9$, and (iii) temperature is inversely proportional to $\phi$ due to the fuel evaporation cooling effect. These results are also consistent with recent experimental findings [63-66]. Following the previous results, temperature and concentration fluctuation RMS, $T^{\prime}$, and $x^{\prime}$ are chosen as $20 \mathrm{~K}$ and 0.1 , respectively, such that similar ranges of $T$ and $\phi$ distributions can be obtained as shown in Fig. 4. In addition, $n$-heptane concentration is initialized to be negatively correlated with temperature. Inhomogeneities of $n-\mathrm{C}_{7} \mathrm{H}_{16}$ and/or $i-\mathrm{C}_{8} \mathrm{H}_{18}$ concentration, in turn, lead to inhomogeneities in the reactivity and equivalence ratio. The corresponding equivalence ratio and PRF fluctuation for each case are listed in Table 3. Since diesel and gasoline fuels are direct-injected by two separate injectors at different times, the initial fields of $n-\mathrm{C}_{7} \mathrm{H}_{16}$ and $\mathrm{PC}_{8} \mathrm{H}_{18}$ are intentionally generated to be unconnected as shown in Fig. $5 \mathrm{a}$.
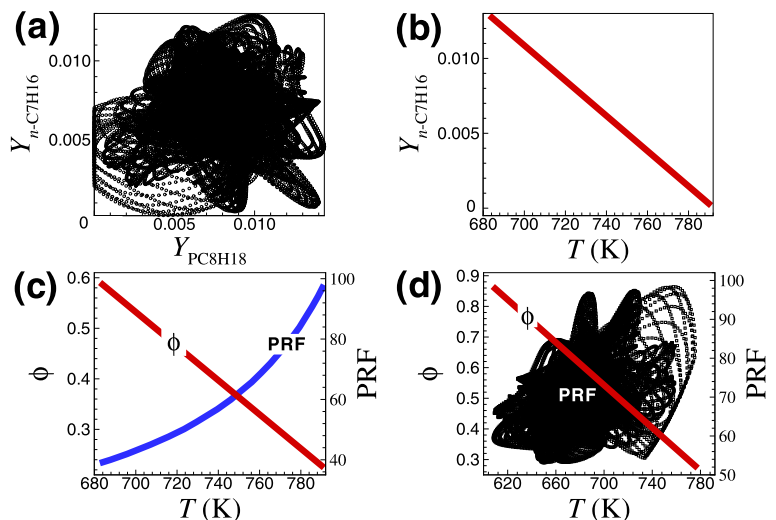

Fig. 5. Initial distributions of (a) the mass fractions of $n$-heptane and psuedo-isooctane, $Y_{n-\mathrm{C} 7 \mathrm{H} 16}-Y_{\mathrm{PC} 8 \mathrm{H} 18}$, (b) $T-Y_{n-\mathrm{C} 7 \mathrm{H} 16}$, and (c) $T-\phi$ and $T-\mathrm{PRF}$, and (d) the distributions of $T-\phi$ and $T-\mathrm{PRF}$ after the injection of $i-\mathrm{C}_{8} \mathrm{H}_{18}$ for Cases 3-8.

The scatter plots in Fig. 5 demonstrate the relations of uncorrelated $Y_{n-\mathrm{C} 7 \mathrm{H} 16}-Y_{\mathrm{PC} 8 \mathrm{H} 18}$, negatively-correlated $T-Y_{n-\mathrm{C} 7 \mathrm{H} 16}$, negatively-correlated $T-\phi$, and T-PRF distribution before and after the $i-\mathrm{C}_{8} \mathrm{H}_{18}$ injection. As can be seen, without the late injection of $i-\mathrm{C}_{8} \mathrm{H}_{18}$, local variations in the PRF number, equivalence ratio, and temperature are connected to each other, which is quantitatively similar to those of a real RCCI engine; however, there is virtually no correlation between $T$ and PRF after the injection of $i-\mathrm{C}_{8} \mathrm{H}_{18}$. As such, the DDFS combustion can be more effective in controlling the reactivity distribution by adjusting the timing/duration/amount of the late $i-\mathrm{C}_{8} \mathrm{H}_{18}$ injection.

The same mean mole fraction of $n-\mathrm{C}_{7} \mathrm{H}_{16}$ and $\mathrm{PC}_{8} \mathrm{H}_{18}$ is intentionally selected (see Table 2), and hence, the temperature drop by the latent heat of evaporation from the direct injection of either $n-\mathrm{C}_{7} \mathrm{H}_{16}$ or $i-\mathrm{C}_{8} \mathrm{H}_{18}$ is likely to be the same. Therefore, a difference in the enthalpy of formations of $\mathrm{PC}_{8} \mathrm{H}_{18}$ and $i-\mathrm{C}_{8} \mathrm{H}_{18}$ is chosen equal to $90,000 \mathrm{erg} / \mathrm{mole}$. This results in a temperature-drop field (see Fig. 6b), which accounts for the evaporation cooling effect of $i-\mathrm{C}_{8} \mathrm{H}_{18}$ injection. The corresponding variance of the temperature drop is approximately $19.2 \mathrm{~K}$. As shown in Fig. 6, the range of each temperature field is nearly the same as approximately $100 \mathrm{~K}$.

A 2-D computational domain of $3.2 \times 3.2 \mathrm{~mm}^{2}$ with $1280 \times$ 1280 grids points was used for all DNSs. The corresponding grid resolution is $2.5 \mu \mathrm{m}$. This fine grid resolution is needed to resolve thin flame structures at high pressure. The DNSs were performed on Shaheen, a 36 rack Cray XC40 system, at King Abdullah University of Science and Technology (KAUST). Each of the DNSs consumed approximately 0.3 million CPU-hours.

\section{Results and discussion}

\subsection{Overall combustion characteristics}

In this section, the effects of $t_{\text {inj }}$ on the combustion characteristics of the DDFS combustion (Cases 3-7) are investigated by examining and comparing the temporal evolutions of the mean pressure and the mean HRR with those of the RCCI combustion (Case 2) as shown in Fig. 7. Several points are to be noted. First, it is readily observed from the figure that Cases 3-7 (DDFS combustion) exhibit much lower peak HRR and longer combustion duration than Case 2 (RCCI combustion) and its corresponding 0-D ignition. This is primarily attributed to elongated combustion by the sequential conversion of $\mathrm{PC}_{8} \mathrm{H}_{18}$ to $i-\mathrm{C}_{8} \mathrm{H}_{18}$ in the DDFS combustion.

Despite the presence of the reactivity inhomogeneity in Case 2, however, an excessive HRR occurs due to a very short combustion duration similar to the 0 -D ignition. This is mainly because the ignition delay decreases exponentially with increasing pressure dur- 


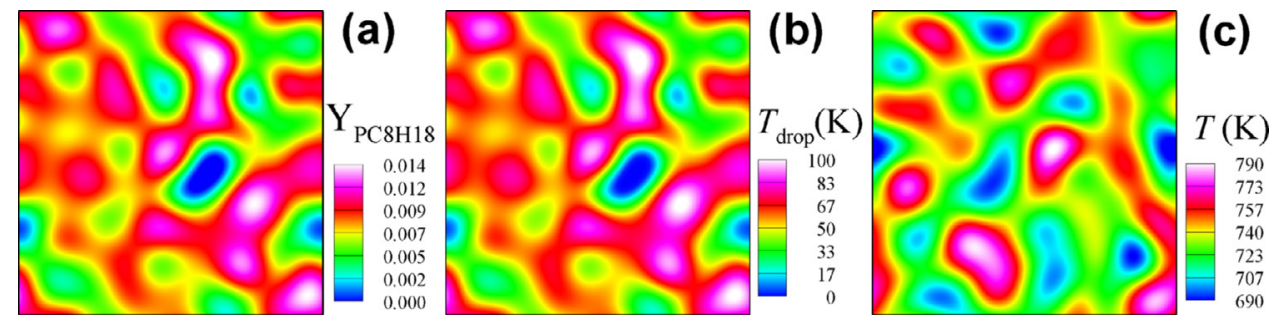

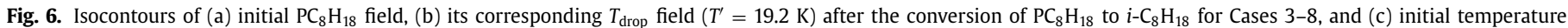
field with $T^{\prime}=20 \mathrm{~K}$ for all Cases $1-8$.
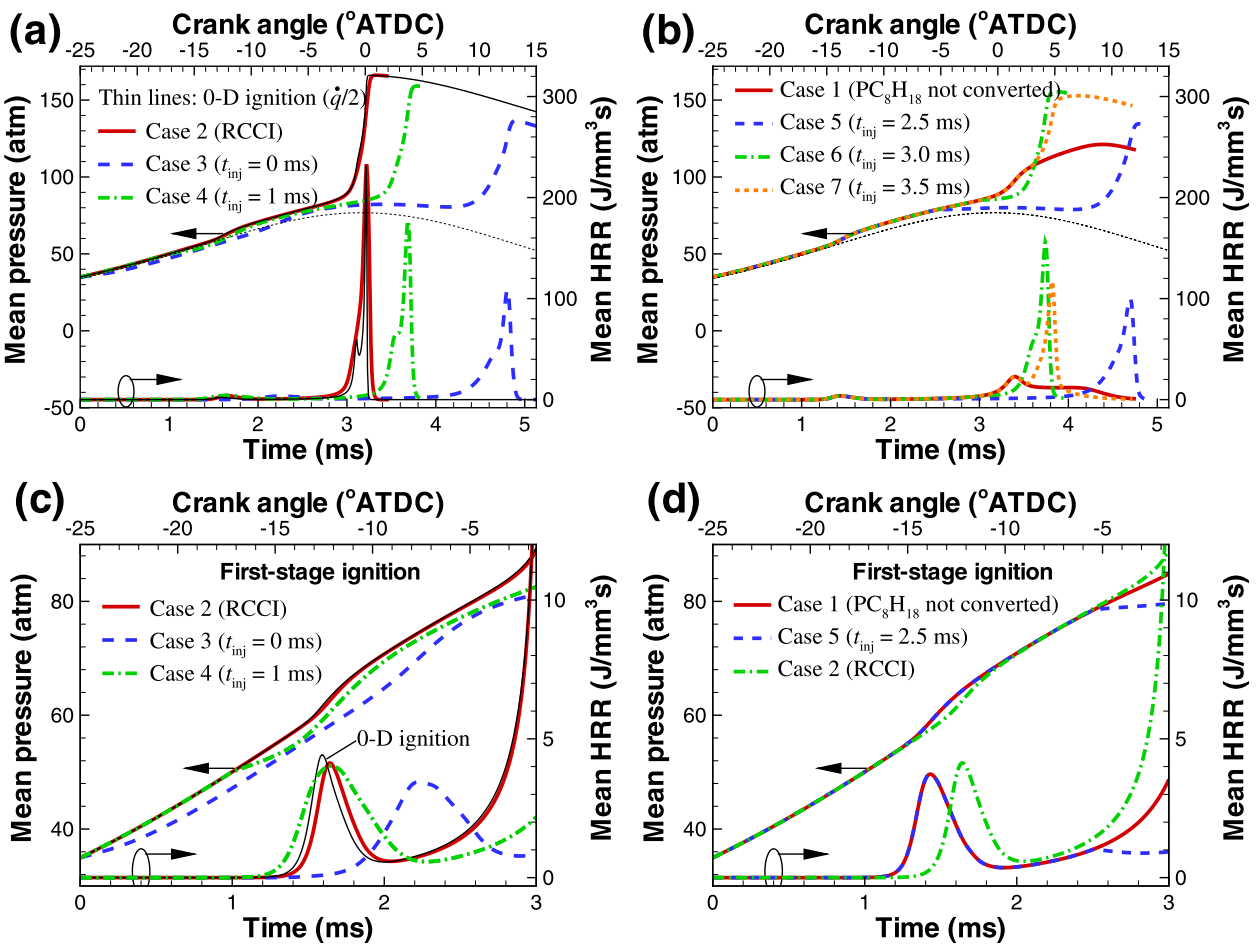

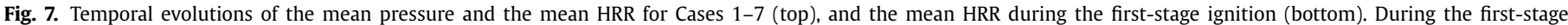
ignition, the temporal evolutions of the mean HRR for Cases 6 ad 7 are identical to that of Case 1 .

ing the compression stroke [67], which eventually removes the differences in the ignition delays of local fuel/air mixtures in Case 2. As such, the RCCI combustion is more likely to occur by the spontaneous ignition mode of combustion rather than the deflagration mode as in the conventional HCCI combustion [39]. In addition, the uncontrolled HRR of Case 2 implies that under very high-pressure condition by the intake boosting as in the present study, an alternative fuel-delivery method like the DDFS should be utilized to alleviate such an excessive HRR. Note that for Case 1, the conversion process of $\mathrm{PC}_{8} \mathrm{H}_{18}$ to $i-\mathrm{C}_{8} \mathrm{H}_{18}$ does not proceed, and hence, its overall equivalence ratio is much lower than those of other cases, leading to the lowest peak HRR. In addition, the widely-distributed HRR in Case 1 is due to the slowdown of the high-temperature chemistry (HTC) of the PRF oxidation under such extremely-diluted conditions as Case 1 with $\phi_{0}=0.41$ and 40\% EGR [68].

Second, the overall DDFS combustion is delayed compared to the RCCI combustion regardless of the injection timing, $t_{\text {inj. This }}$ can simply be understood by the effects of the late delivery of isooctane and subsequent evaporating cooling on the DDFS combustion. Moreover, it is also observed that the ignition delay, $\tau_{\text {ig }}$, of Cases 3-7 features a non-monotonic behavior with increasing $t_{\text {inj }}$ : i.e. $\tau_{\text {ig }}$ first decreases from $t_{\text {inj }}=0$ to $1.0 \mathrm{~ms}$; it increases from $t_{\text {inj }}$ $=1.0$ to $2.5 \mathrm{~ms}$; it decreases again from $t_{\text {inj }}=2.5$ to $3.0 \mathrm{~ms}$; finally, it increases a little bit from $t_{\mathrm{inj}}=3.0$ to $3.5 \mathrm{~ms}$. This non- monotonic behavior of $\tau_{\text {ig }}$ is also attributed to the evaporation cooling effect of directly-injected $i-\mathrm{C}_{8} \mathrm{H}_{18}$ together with its injection timing relative to the first- and second-stage ignition of the baseline case (Case 1). Prior to examining the DNS cases, it should be noted that a misfire occurs for Case 8 with $t_{\text {inj }}=2.0$ ms because the temperature drop by the injection of $i-\mathrm{C}_{8} \mathrm{H}_{18}$ prohibits the occurrence of the main combustion at the right moment. This issue will be discussed in the following section.

For Case 3, the direct injection of $i-\mathrm{C}_{8} \mathrm{H}_{18}$ is finished much earlier than the onset of the first-stage ignition of the baseline case. Therefore, the drop of temperature and pressure by the evaporation cooling of $i-\mathrm{C}_{8} \mathrm{H}_{18}$ (i.e. $\Delta T \approx 54 \mathrm{~K}$ and $\Delta P_{\mathrm{t}} \approx 2.8 \mathrm{~atm}$ at the end of $i-\mathrm{C}_{8} \mathrm{H}_{18}$ injection) is large enough to delay the occurrence of the first-stage ignition, thereby retarding the main combustion significantly. For Case 4 , however, $i-\mathrm{C}_{8} \mathrm{H}_{18}$ is gradually supplied during the early stage of the first-stage ignition as shown in Fig. 7c, and hence, the drop of temperature and pressure becomes marginal (i.e. $\Delta T \approx 24 \mathrm{~K}$ and $\Delta P_{\mathrm{t}} \approx 1.3 \mathrm{~atm}$ ), which consequently delays the main combustion to a small extent compared to that of Case 3.

On the contrary, the ignitions of Cases 5-7 exhibit different characteristics compared to those of Cases 3 and 4 due to $t_{\text {inj }}$ greater than $\tau_{\mathrm{ig}, 1}$ of the baseline case. The injection of $i-$ $\mathrm{C}_{8} \mathrm{H}_{18}$ for Case 5 starts at $t_{\text {inj }}=2.5 \mathrm{~ms}\left(-5.5^{\circ} \mathrm{CA}\right.$ ATDC). At 

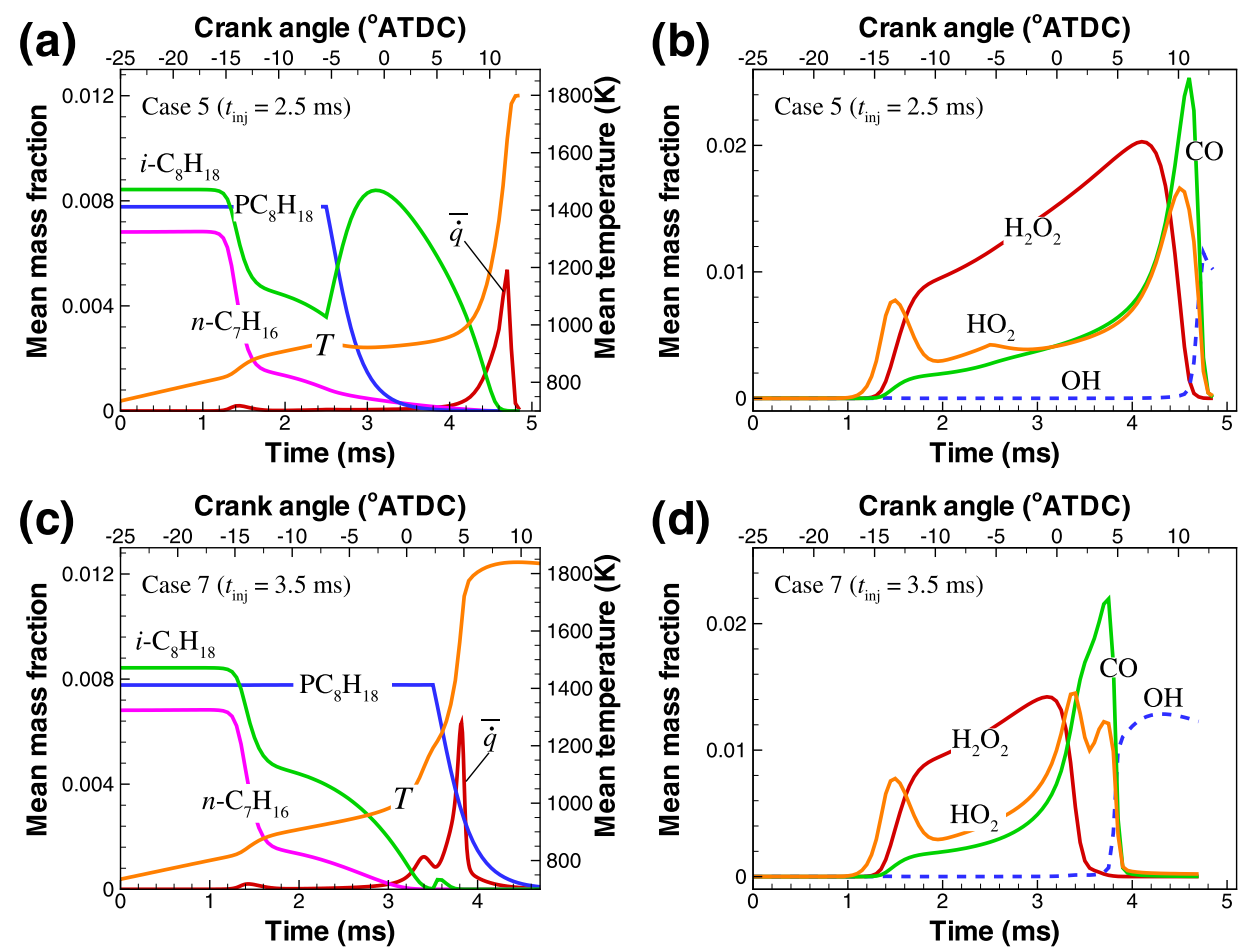

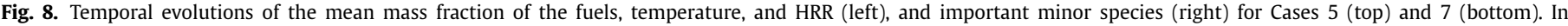
order to display in the same scale, the mean mass fractions of $\mathrm{H}_{2} \mathrm{O}_{2}, \mathrm{OH}$, and $\mathrm{HO}_{2}$ species are increased by a factor of 8 , 100 , and 100 , respectively.

this moment, the temperatures of local mixtures are in the range of 930 to $946 \mathrm{~K}$ (not shown here) which corresponds to the intermediate-temperature chemistry (ITC) regime of the PRF oxidation $[34,36,51,52]$. For Cases 6 and 7, the $\mathrm{PC}_{8} \mathrm{H}_{18}$ conversion to $i-\mathrm{C}_{8} \mathrm{H}_{18}$ starts at 3.0 and $3.5 \mathrm{~ms}$, respectively, at which the temperature range of local mixtures (e.g., $1050 \leq T \leq 1270$ for Case 7) corresponds to the HTC regime. Therefore, the $i-\mathrm{C}_{8} \mathrm{H}_{18}$ injection comes to affect the ITC for Case 5 and the HTC for Cases 6 and 7, respectively.

More specifically, the overall combustion of Case 5 is more delayed than those of Cases 6 and 7 due to the adverse effect of temperature drop on the ITC. This is manifested in the retardation of the main ITC reactions: $\mathrm{H}+\mathrm{O}_{2}+\mathrm{M} \rightarrow \mathrm{HO}_{2}(\mathrm{R} 1), \mathrm{RH}+\mathrm{HO}_{2}$ $\rightarrow \mathrm{R}+\mathrm{H}_{2} \mathrm{O}_{2}$ (R2), and $\mathrm{H}_{2} \mathrm{O}_{2}+\mathrm{M} \rightarrow \mathrm{OH}+\mathrm{OH}+\mathrm{M}$ (R3), where $\mathrm{RH}$ represents a fuel molecule. In general, the hydrogen peroxide decomposition reaction of $\mathrm{R} 3$, which is one of the key reactions to initiate the HTC in the second-stage ignition, becomes active above approximately $1000 \mathrm{~K}[69,70]$, and hence, the mixtures need a longer time to overcome the temperature drop and render the HTC to start.

To verify the effect of temperature drop on the ITC and HTC of Cases 5 and 7, the temporal evolutions of the mean mass fractions of fuel and important minor species are shown in Fig. 8 together with those of the mean temperature and HRR. It is readily observed from the figure that for Case 5 , the mass fraction of $i-\mathrm{C}_{8} \mathrm{H}_{18}, Y_{i-\mathrm{C} 8 \mathrm{H} 18}$, increases right after the conversion of $\mathrm{PC}_{8} \mathrm{H}_{18}$ to $i-\mathrm{C}_{8} \mathrm{H}_{18}$ and then, decreases while $Y_{\mathrm{H} 2 \mathrm{O} 2}$ also keeps increasing till the start of the second-stage ignition. For Case 7, however, $Y_{i-\mathrm{C} 8 \mathrm{H} 18}$ keeps decreasing even after the $i-\mathrm{C}_{8} \mathrm{H}_{18}$ injection and $Y_{\mathrm{H} 2 \mathrm{O} 2}$ almost vanishes prior to the $i-\mathrm{C}_{8} \mathrm{H}_{18}$ injection. These results demonstrate that for Case 5 , the temperature drop by the $i-\mathrm{C}_{8} \mathrm{H}_{18}$ injection retards the decomposition and consumption of $i-\mathrm{C}_{8} \mathrm{H}_{18}$ and prohibits the $\mathrm{H}_{2} \mathrm{O}_{2}$ decomposition, consequently delaying the beginning of the high-temperature heat release (HTHR). Moreover, they also indicate that for Case 7, the effect of temperature drop on the HTC is marginal because under the HTC regime, the in- jected $i-\mathrm{C}_{8} \mathrm{H}_{18}$ immediately converts into small fragments, down to $\mathrm{CH}_{2} \mathrm{O}, \mathrm{HCO}, \mathrm{H}_{2} \mathrm{O}_{2}, \mathrm{HO}_{2}$, and $\mathrm{CO}$ due to highly active $\mathrm{HTC}$ and hence, the HTHR easily overcomes the temperature drop induced by $i-\mathrm{C}_{8} \mathrm{H}_{18}$ injection.

Third, unlike Cases 3-5 in which the ignition characteristics such as the ignition timing and combustion duration are not well controlled by the injection of $i-\mathrm{C}_{8} \mathrm{H}_{18}$, the main combustion in Cases 6 and 7 occurs right after the beginning of the $i-\mathrm{C}_{8} \mathrm{H}_{18}$ injection. As explained above, the fuel/air charge in Cases 6 and 7 has already undergone the HTC regime before the injection of $i-\mathrm{C}_{8} \mathrm{H}_{18}$. Under the HTC regime, the injected $i-\mathrm{C}_{8} \mathrm{H}_{18}$ burns immediately, and hence, the consumption of $i-\mathrm{C}_{8} \mathrm{H}_{18}$ coincides with the production of heat. As such, the injection rate of $i-\mathrm{C}_{8} \mathrm{H}_{18}$ directly controls the consumption rate of $i-\mathrm{C}_{8} \mathrm{H}_{18}$, which in turn governs the rate and peak of heat release of the main combustion. These results are consistent with those in Wissink and Reitz $[13,14]$. They demonstrated that the DDFS combustion is controlled by the mixing of the directly-injected fuel, which is referred to as 'diffusion-limited injection'. The timing and duration of the diffusion-limited injection allows a precise control of the HRR and PRR of the DDFS combustion. They also found that the late direct fuel injection should start after the end of the LTHR to fully utilize the advantage of the diffusion-limited injection while the $t_{\text {inj }}$ also needs to be adjusted by considering a trade-off between $\mathrm{NO}_{\mathrm{x}}$ and soot emissions.

In summary, the DDFS combustion can be used as an alternative to HCCI combustion under very high-pressure conditions because it can effectively control the ignition timing and alleviate the peak HRR by adjusting the injection timing. Furthermore, the DDFS combustion can precisely control the occurrence of the main combustion especially when the direct injection of fuel starts during the HTC regime.

\subsection{Combustion mode analysis}

In previous studies [21,71], it was found that as the degree of thermal inhomogeneity of the fuel/air charge increases at the on- 

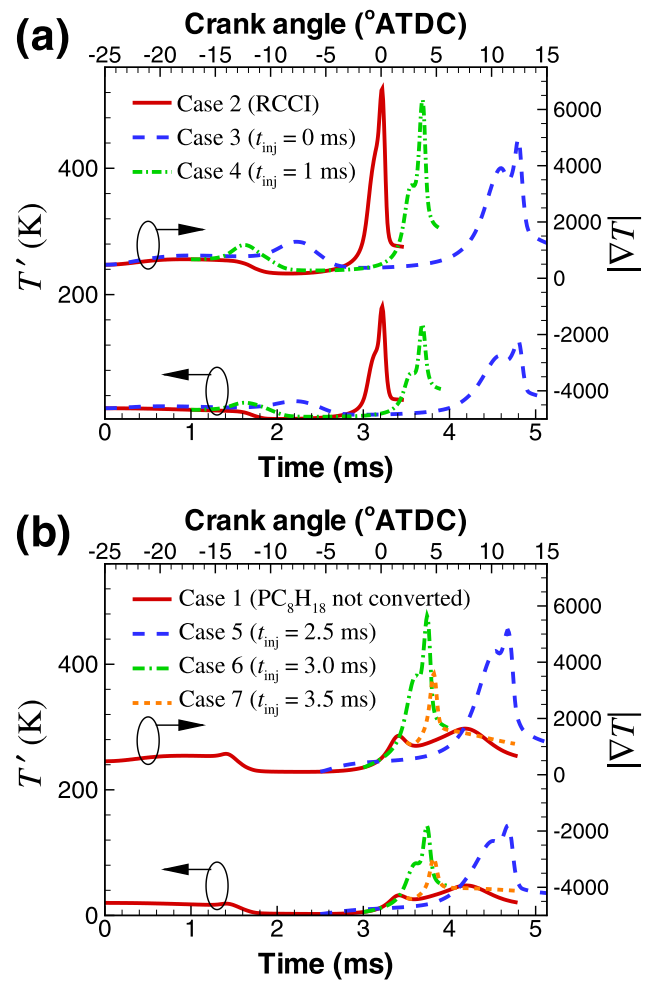

Fig. 9. Temporal evolutions of the mean temperature fluctuation RMS and the mean temperature gradient for Cases 1-7.

set of the main combustion, the overall combustion is more likely to occur by the deflagration mode of combustion, which in turn reduces the peak HRR by slowing down the overall combustion process and prolonging the combustion duration. In addition, it was also found that the negatively-correlated $T-\phi$ distribution in the mixture has an adverse effect on the HCCI combustion because the evaporation cooling effect of direct fuel injection offsets that of mixture inhomogeneity by narrowing the differences in the ignition delays of local fuel/air mixtures with different reactivity, consequently leading to a shorter combustion duration and an excessive HRR [23,33,38,71-73]. Recently, Bansal et al. [38] demonstrated that the HCCI combustion with compression heating is more apt to occur by the spontaneous ignition mode than that under constant volume because the compression heating tends to reduce temperature gradients before the main combustion.

As one of the variants of the HCCI combustion, therefore, the DDFS combustion has both advantages and disadvantages over the $\mathrm{HCCl}$ combustion in developing the deflagration mode of combustion. To investigate the effects of the late injection of $i-\mathrm{C}_{8} \mathrm{H}_{18}$ into the burning charge on the DDFS combustion mode, therefore, we first measure the degree of thermal inhomogeneity by evaluating the temporal evolutions of the temperature variance, $T^{\prime}$, and the mean temperature gradient, $|\nabla T|$, for Cases 1-7 as shown in Fig. 9.

It is readily observed that both of $T^{\prime}$ and $|\nabla T|$ almost vanish after each first-stage ignition of Cases 3-7. Such small $T^{\prime}$ and $|\nabla T|$ prior to the main combustion are more apt to induce the spontaneous ignition fronts with a short combustion duration like Case 2. Therefore, the predominance of the spontaneous ignition mode may be expected for all the DDFS cases.

To further investigate the characteristics of instantaneous DDFS combustion mode, the isocontours of normalized HRR for Cases 13,5 , and 7 at different times of $15 \%, 40 \%, 50 \%$, and $80 \%$ cumulative mean HRR are shown in Fig. 10. As shown in the figure, the instantaneous RCCI combustion of Case 1 and 2 seems to occur al- most simultaneously throughout the entire domain by the spontaneous ignition mode. For the DDFS combustion of Cases 3 and 5 , however, strong heat release occurs in several thin flame-like fronts while weak heat is also released in broad regions during the early phase of combustion (up to 50\% CHRR time). During the later phase of combustion, most heat seems to be released in thicker regions by the spontaneous ignition mode. These results suggest that the spontaneous ignition mode can be predominant for the RCCI combustion while a mixed mode of combustion seems to occur in the DDFS combustion (Cases 3 and 5). Unlike Cases 3 and 5 , however, the combustion of Case 7 seems to occur over a broad area by the spontaneous ignition mode.

To figure out whether the local thin reaction fronts in Case 5 are a deflagration wave or not, a budget analysis is carried out by comparing the relative magnitudes of reaction and diffusion terms of a given species equation as in $[24,38,39,74]$. For the analysis, CO radical is adopted because it is one of the most important species in a deflagration wave via its conversion reaction to $\mathrm{CO}_{2}$ (i.e. $\mathrm{CO}+$ $\left.\mathrm{OH} \rightarrow \mathrm{CO}_{2}+\mathrm{H}\right)[34,36,51,52,70]$. Figure 11 shows the isocontours of the normalized HRR and the scatter plot and several cut plots of the reaction and diffusion rates of $\mathrm{CO}$ at $40 \%$ CHRR time.

As shown in the scatter plot of Fig. 11b, the reaction terms generally have much greater absolute values than the diffusion terms, which implies that the DDFS combustion of Case 5 occurs primarily by the spontaneous ignition mode rather than the deflagration mode. However, the peak HRR coincides with the peak diffusion and reaction rates of $\mathrm{CO}$ species, which also corresponds with the thin reaction fronts in Fig. 11a. This is one of the characteristics of a deflagration wave, suggesting that the thin reaction fronts can be a deflagration wave. Note that in the diffusive limit of 1-D laminar simulations, where the diffusive limit represents deflagration wave propagation without auto-ignition $[19,22,60]$, the reaction term of $\mathrm{CO}$ is 2-4 times greater that its diffusion term. This is because although the reaction front propagates under the diffusive limit, the mixture upstream of the front is already highly reactive, and thus, the reaction term is somewhat larger than the diffusion term.

The local cut plots of the reaction fronts verify their characteristics as a deflagration wave. As readily observed in the cut plots of A, B, and D in Fig. 11, the absolute values of diffusion rates are comparable to the reaction rates, considering their relative magnitudes in the diffusive limit. This indicates that the reaction fronts of $A, B$, and $D$ are representative of a deflagration wave. Note that the combustion wave at cut $C$ results from a mergence of two deflagration waves, and as such, the reaction term is significantly greater than the diffusion term.

Finally, the Damköhler number analysis is performed to quantitatively evaluate the deflagration mode of combustion. The Damköhler number, $D a$, is defined as [19-23,33-35]:

$D a=\frac{\dot{\omega}_{k}}{\left|-\nabla \cdot\left(\rho Y_{k} \mathbf{V}_{k}\right)\right|}$,

where $Y_{k}, \mathbf{V}_{k}$, and $\dot{\omega}_{k}$ denote the mass fraction, diffusion velocity, and net production rate of species $k$, respectively. $Y_{c} \equiv Y_{r m O_{2}}+Y_{\mathrm{CO}}$ is used for the Damköhler number analysis. As mentioned above and in previous studies [19,21,33-35], $D a$ value in the diffusive limit is found to be approximately 4.0 through a series of 1-D laminar simulations of which initial conditions are the same as those of the 2-D DNSs. As such, local combustion is determined to occur by the deflagration mode when its $D a$ is less than 4.0.

Figure 12 shows the temporal evolutions of the fraction of HRR from the deflagration mode for Cases 1-7. It is readily observed that up to $30 \%$ of heat is released in the deflagration mode between the first- and second-stage ignition. During the main combustion, however, most of heat release occurs in the spontaneous ignition mode. As a result, the total heat release from the deflagra- 


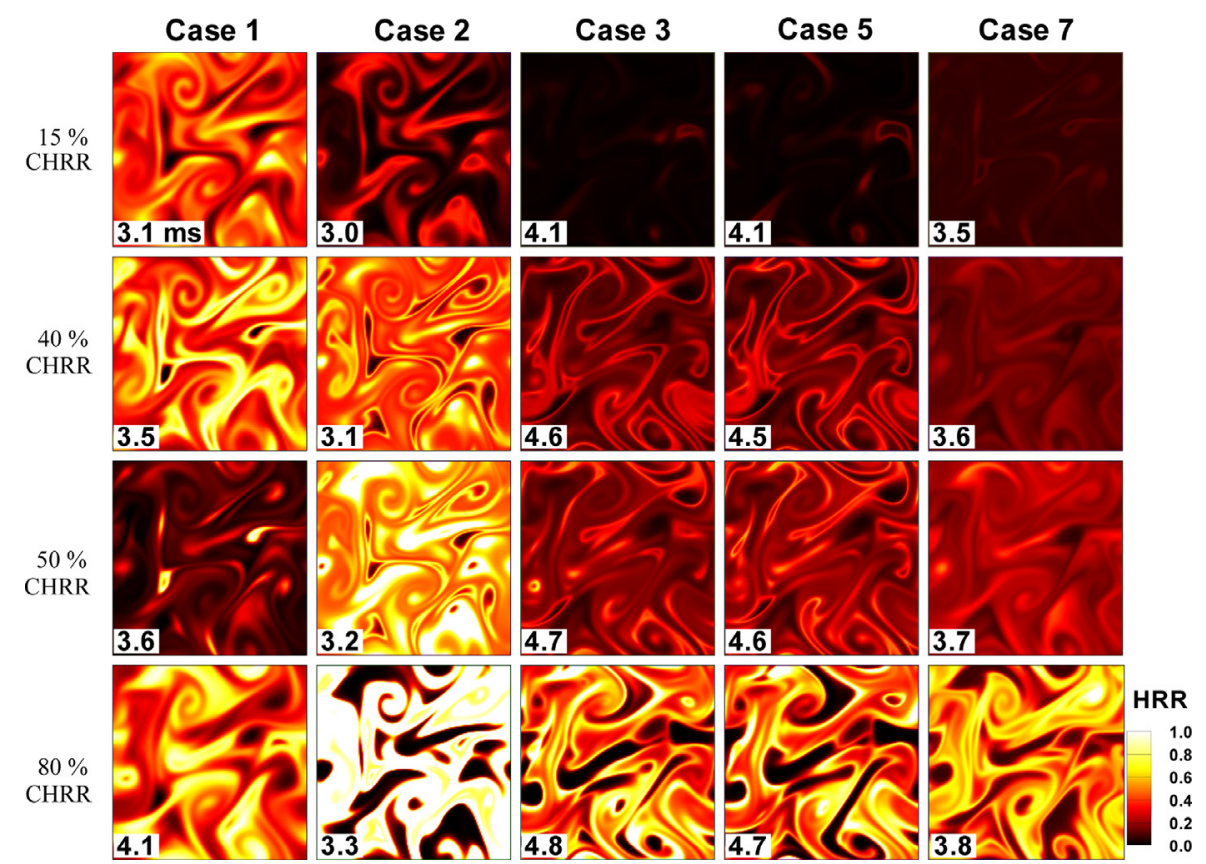

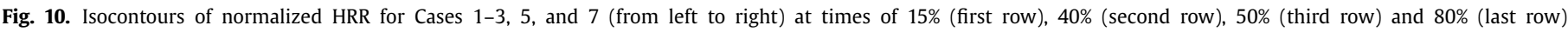
cumulative heat release rate (CHRR).

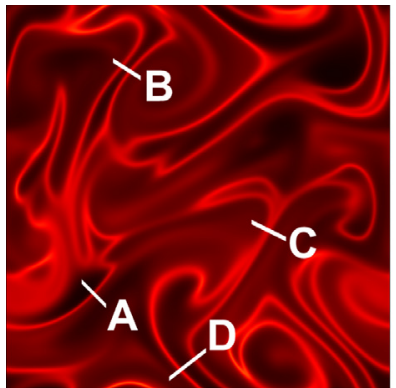

(a)
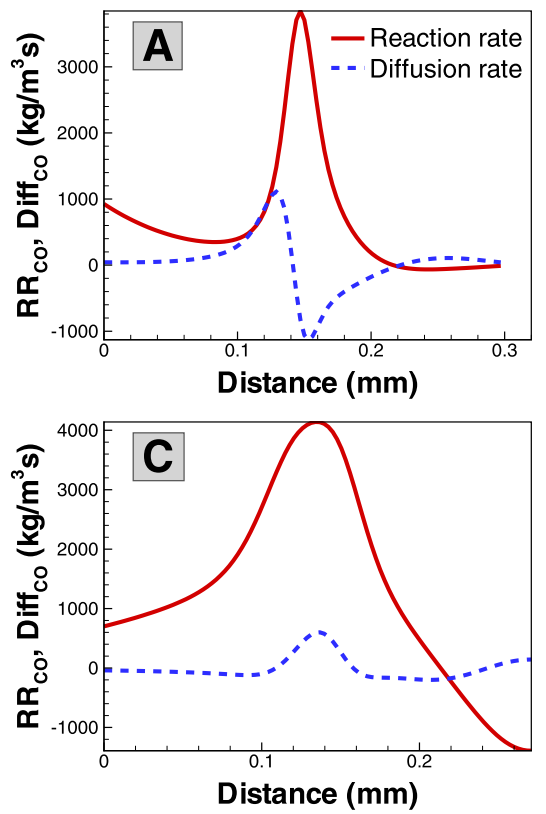
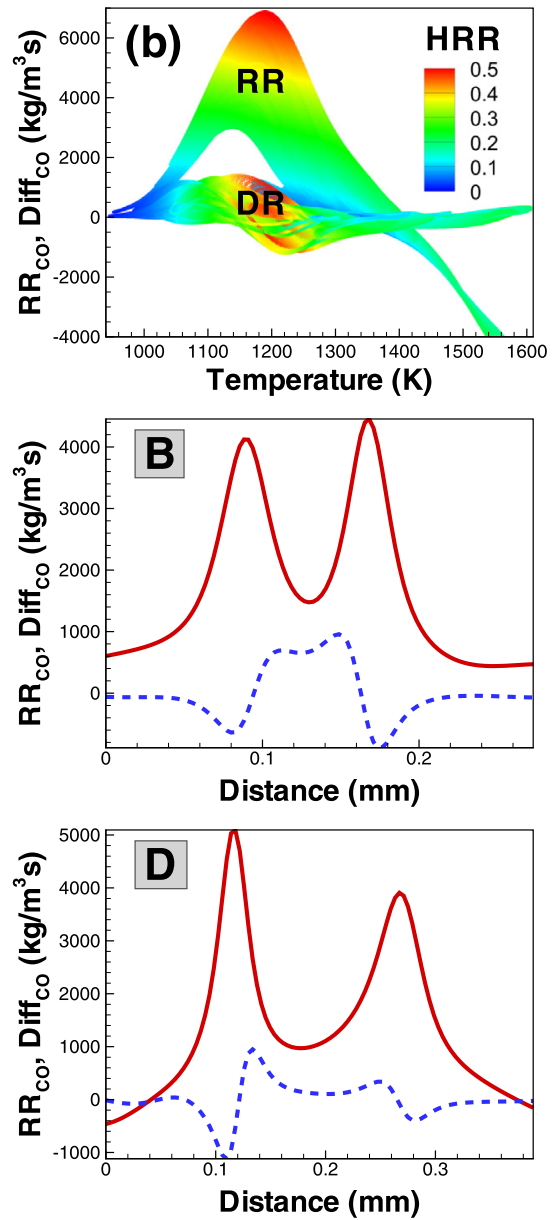

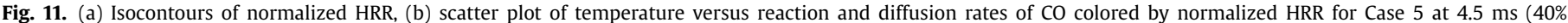
cumulative HRR), and (A)-(D) spatial profiles of reaction and diffusion rates of CO along each cut line in (a). 

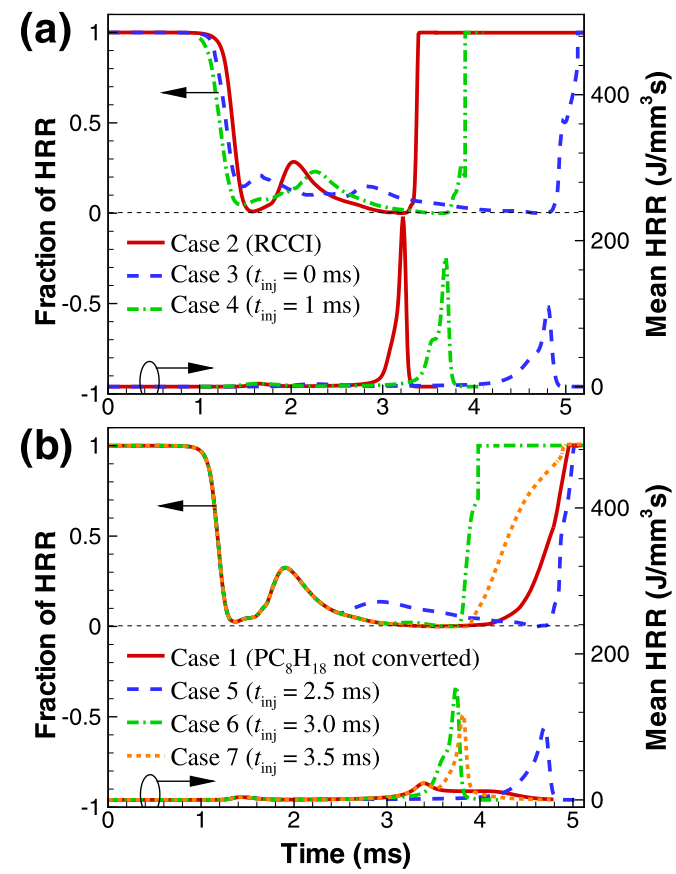

Fig. 12. Temporal evolutions of the fraction of HRR from the deflagration mode and the mean HRR for Cases 1-7.

tion mode for Cases 3 and 5 is approximately 5.5\% while those for other Cases are less than 3\%.

In summary, the budget analysis and the Damköhler number analysis verify that although a mixed combustion mode of both deflagration and spontaneous ignition exists during the early phase of the DDFS combustion (Cases 5 and 7), the spontaneous ignition is the dominant combustion mode for both DDFS and RCCI combustion. These results suggest that the spread-out of the HRR in the DDFS combustion is attributed not to the deflagration but to the sequential injection of $i-\mathrm{C}_{8} \mathrm{H}_{18}$.

\subsection{Misfire}

As mentioned earlier, a misfire occurs for Case 8 with $t_{\text {inj }}=$ $2.0 \mathrm{~ms}$. It is also found from a series of 0 -D simulations that a misfire occurs for the DDFS combustion with $t_{\text {inj }}=1.3 \sim 2.2 \mathrm{~ms}$. It seems that the misfire may occur due to the large temperature drop by the late $i-\mathrm{C}_{8} \mathrm{H}_{18}$ injection. To verify the temperature drop effect on the misfire, therefore, one additional 2-D DNS (Case 9) is carried out. The initial conditions for Cases 8 and 9 with $t_{\text {inj }}$ $=2.0 \mathrm{~ms}$ are identical except for the degree of temperature drop by the late $i-\mathrm{C}_{8} \mathrm{H}_{18}$ injection. The temperature drop by the $i-\mathrm{C}_{8} \mathrm{H}_{18}$ injection in Case 9 is set to a half of those of other DDFS cases (Cases 3-8), which is realized by changing the difference in the enthalpy of formations of $i-\mathrm{C}_{8} \mathrm{H}_{18}$ and $\mathrm{PC}_{8} \mathrm{H}_{18}$ from 90,000 to 45,000 erg/mole.

Figure 13 shows the temporal evolutions of the mean pressure and temperature, and the maximum temperature, $T_{\max }$, together with the mean HRR and the mean mass fraction of some important species for Cases 8 and 9. As readily observed in the figure, the second-stage ignition for Case 8 fails to occur while it successfully occurs for Case 9 . The misfire for Case 8 is primarily attributed to the effect of the large temperature drop by $i-\mathrm{C}_{8} \mathrm{H}_{18}$ evaporation on the combustion together with the expansion cooling effect after the TDC. The temporal evolution of the maximum $T_{\max }$ reveals that for Case $9, T_{\max }$ increases gradually up to $1000 \mathrm{~K}$ at $3.6 \mathrm{~ms}\left(3^{\circ} \mathrm{CA}\right.$ ATDC) and the main combustion commences afterwards. For Case 8 , however, $T_{\max }$ remains nearly the same as approximately $970 \mathrm{~K}$
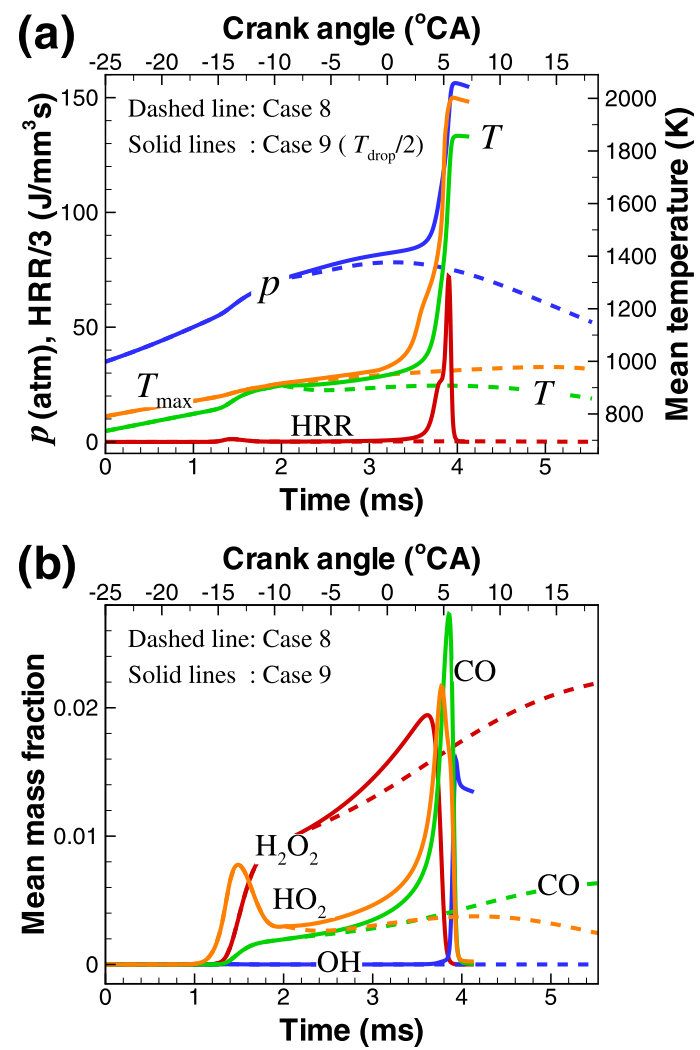

Fig. 13. Temporal evolutions of (a) the mean pressure, the mean temperature, the mean HRR, and the maximum temperature, and (b) the mean mass fractions of $\mathrm{OH}$, $\mathrm{CO}, \mathrm{HO}_{2}$, and $\mathrm{H}_{2} \mathrm{O}_{2}$ for Cases 8 and 9 . In order to display in the same scale, the mean mass fractions of $\mathrm{H}_{2} \mathrm{O}_{2}$ and $\mathrm{HO}_{2}$ species are increased by a factor of 8 and 100 , respectively.
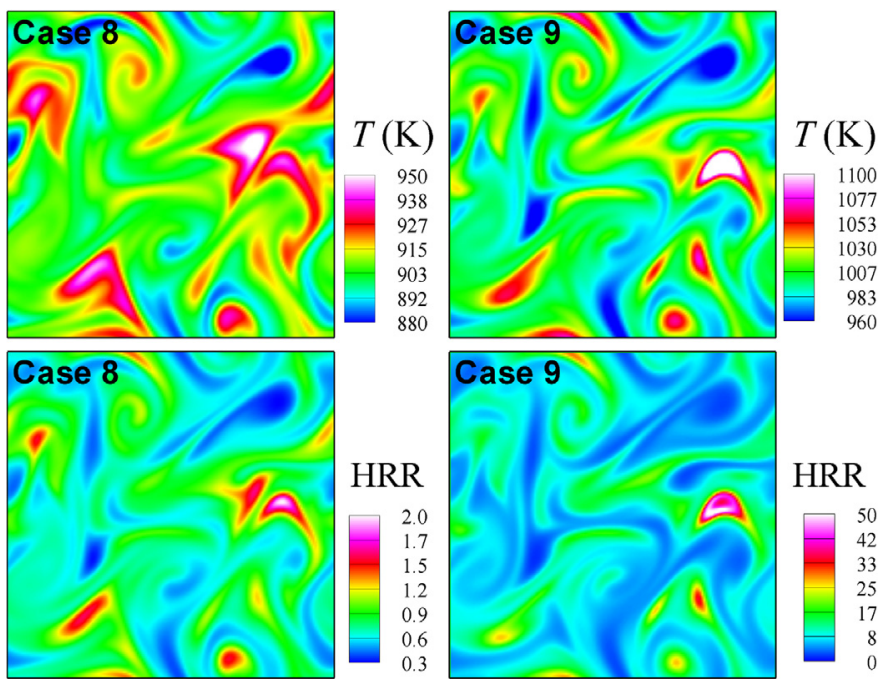

Fig. 14. Isocontours of temperature (top) and HRR (bottom) for Cases 8 and 9 at $3.6 \mathrm{~ms}\left(3^{\circ} \mathrm{CA}\right.$ ATDC)

even after $3^{\circ} \mathrm{CA}$ ATDC. As mentioned earlier, this temperature is not high enough to trigger the HTC. Moreover, the mean temperature and pressure of the fuel/air charge continuously decrease after the TDC due to the expansion without significant heat release from the charge, which ultimately leads to the misfire.

To further identify the effect of temperature drop by the $i-\mathrm{C}_{8} \mathrm{H}_{18}$ injection, the instantaneous isocontours of HRR for Cases 8 and 9 at $3.6 \mathrm{~ms}$ are shown in Fig. 14. It is readily observed that for Case 8 , the HRR from nascent ignition kernels becomes very weak and 
their corresponding local temperatures are much less than $1000 \mathrm{~K}$ such that the conversion of the ITC to the HTC cannot occur. On the contrary, for Case 9, the HRR from ignition kernels becomes high enough and most of the corresponding local temperatures are greater than $1000 \mathrm{~K}$ such that the HTC can successfully take over from the ITC as the main chemistry in the ignition kernels, eventually leading to a success of combustion.

These results indicate that a successful development of the second-stage ignition in the DDFS combustion highly depends on the degree of temperature drop by the late $i-\mathrm{C}_{8} \mathrm{H}_{18}$ injection. In RCCI engine experiments, Kokjohn et al. [64] observed a small drop of the mean pressure and temperature by a late direct injection, which is actually less than those in the present study. This is because in reality, the directly-injected fuel can occupy only a part of the engine cylinder such that the overall temperature and pressure drop is less than that considered in the present DNS configuration. In fact, the temperature drop in the present DNSs with a limited domain size represents that in a region where $i-\mathrm{C}_{8} \mathrm{H}_{18}$ fuel is directly injected.

\section{Conclusions}

The ignition characteristics of lean PRF/air/EGR mixture under the DDFS and RCCI conditions were investigated by 2-D DNSs with a 116-species reduced mechanism. The 2-D DNSs of the DDFS combustion were performed by varying the injection timing of $i-\mathrm{C}_{8} \mathrm{H}_{18}$ with a pseudo-iso-octane model which was newly developed to mimic the timing, duration, and cooling effects of the direct injection of $i-\mathrm{C}_{8} \mathrm{H}_{18}$ onto a premixed background charge of PRF/air/EGR mixture. A novel compression heating model was also incorporated in the DNSs to account for the compression heating and expansion cooling effects of the piston motion in an engine cylinder.

It was found that under high-pressure conditions, the RCCI combustion occurs very fast with an excessive HRR due to the dominance of the spontaneous ignition while the DDFS combustion exhibits much lower peak HRR and longer combustion duration regardless of the fuel-injection timing because of the sequential injection of $i-\mathrm{C}_{8} \mathrm{H}_{18}$. It was also found that the ignition delay of the DDFS combustion features a non-monotonic behavior with increasing fuel-injection timing. This is primarily attributed to the evaporation cooling effect of the directly-injected $i-\mathrm{C}_{8} \mathrm{H}_{18}$ on the LTC, ITC, and HTC of the PRF oxidation, which is determined by the injection timing relative to the first- and second-stage ignition of the baseline case. Especially when $i-\mathrm{C}_{8} \mathrm{H}_{18}$ is delivered during the secondstage ignition, the injection rate of $i-\mathrm{C}_{8} \mathrm{H}_{18}$ can directly control its consumption rate due to the highly-reactive HTC, which in turn manipulates the rate and peak of heat release of the main combustion. It was further identified from the budget and Damköhler number analyses that although a mixed combustion mode of both deflagration and spontaneous ignition exists during the early phase of the DDFS combustion, the spontaneous ignition becomes predominant for the main DDFS combustion, and hence, the spreadout of HRR in the DDFS combustion is solely determined by the direct injection process of $i-\mathrm{C}_{8} \mathrm{H}_{18}$. Finally, a misfire was observed in the DDFS combustion when the direct injection of $i-\mathrm{C}_{8} \mathrm{H}_{18}$ occurs during the ITC regime between the first- and second-stage ignition. This is mainly because the temperature drop induced by the direct injection of $i-\mathrm{C}_{8} \mathrm{H}_{18}$ prevents the main ITC reactions from inducing the HTC even after the TDC, and hence, the main combustion related to the HTC fails to occur.

These results demonstrate that the DDFS combustion can allow a precise control of the combustion phasing and the peak HRR by adjusting the injection timing of $i-\mathrm{C}_{8} \mathrm{H}_{18}$. Moreover, the rate and duration of the main DDFS combustion can effectively be controlled when the direct injection of $i-\mathrm{C}_{8} \mathrm{H}_{18}$ occurs during the HTC regime.

\section{Acknowledgment}

This research was supported by Basic Science Research Program through the National Research Foundation of Korea (NRF) funded by the Ministry of Science, ICT \& Future Planning (No. 2015R1A2A2A01007378). This research used the resources of the KAUST Supercomputing Laboratory and UNIST Supercomputing Center. The work at ORNL used resources of the Oak Ridge Leadership Computing Facility, which is supported by the Office of Science of the U.S. Department of Energy under Contract No. DEAC05-000R22725.

\section{References}

[1] J.E. Dec, Advanced compression-ignition engines-understanding the in-cylinder processes, Proc. Combust. Inst. 32 (2009) 2727-2742.

[2] M. Yao, Z. Zheng, H. Liu, Progress and recent trends in homogeneous charge compression ignition (HCCI) engines, Prog. Energy Combust. Sci. 35 (2009) 398-437.

[3] X. Lü, D. Han, Z. Huang, Fuel design and management for the control of advanced compression-ignition combustion modes, Prog. Energy Combust. Sci. 37 (2011) 741-783.

[4] S. Saxena, I.D. Bedoya, Fundamental phenomena affecting low temperature combustion and HCCI engines, high load limits and strategies for extending these limits, Prog. Energy Combust. Sci. 39 (2013) 457-488.

[5] S.L. Kokjohn, R.M. Hanson, D.A. Splitter, R.D. Reitz, Fuel reactivity controlled compression ignition (RCCI): a pathway to controlled high-efficiency clean combustion, Int. J. Engine Res. 12 (2011) 209-226.

[6] R.D. Reitz, G. Duraisamy, Review of high efficiency and clean reactivity controlled compression ignition (RCCI) combustion in internal combustion engines, Prog. Energy Combust. Sci. 46 (2015) 12-71.

[7] A. Paykani, A.-H. Kakaee, P. Rahnama, R.D. Reitz, Progress and recent trends in reactivity-controlled compression ignition engines, Int. J. Engine Res. (2016) 481-524.

[8] D. Splitter, R. Hanson, S. Kokjohn, R. Reitz, Reactivity controlled compression ignition (RCCI) heavy-duty engine operation at mid-and high-loads with conventional and alternative fuels, SAE paper 2011-01-0363SAE. (2011).

[9] S.L. Kokjohn, D.A. Splitter, R.M. Hanson, R.D. Reitz, V. Manente, B. Johansson, Modeling charge preparation and combustion in diesel fuel, ethanol, and dual-fuel PCCI engines, Atom. Sprays 21 (2011) 107-119.

[10] D.E. Nieman, A.B. Dempsey, R.D. Reitz, Heavy-duty RCCI operation using natural gas and diesel, SAE Int. J. Engines 5 (2012) 270-285.

[11] Y. Zhang, I. Sagalovich, W. De Ojeda, A. Ickes, T. Wallner, D.D. Wickman, Development of dual-fuel low temperature combustion strategy in a multi-cylinder heavy-duty compression ignition engine using conventional and alternative fuels, SAE Int. J. Engines 6 (2013) 1481-1489.

[12] J.H. Lim, R.D. Reitz, High load (21 bar IMEP) dual fuel RCCI combustion using dual direct injection, J. Eng. Gas. Turbines Power-Trans. ASME 136 (2014) 101514-101514.

[13] M. Wissink, R.D. Reitz, Direct dual fuel stratification, a path to combine the benefits of RCCI and PPC, SAE Int. J. Engines 8 (2015) 878-889.

[14] M. Wissink, R. Reitz, Exploring the role of reactivity gradients in direct dual fuel stratification, SAE Int. J. Engines 9 (2016) 1036-1048.

[15] M. Wissink, R. Reitz, The role of the diffusion-limited injection in direct dual fuel stratification, Int. J. Engine Res. 18 (2017) 351-365.

[16] C. Kavuri, J. Paz, S.L. Kokjohn, A comparison of reactivity controlled compression ignition (RCCI) and gasoline compression ignition (GCI) strategies at high load, low speed conditions, Energy Conv. Manag. 127 (2016) 324-341.

[17] J.E. Dec, Y. Yang, N. Dronniou, Improving efficiency and using e10 for higher loads in boosted HCCI engines, SAE Int. J. Engines 5 (3) (2012) 1009-1032.

[18] R. Sankaran, H.G. Im, E.R. Hawkes, J.H. Chen, The effects of non-uniform temperature distribution on the ignition of a lean homogeneous hydrogen-air mixture, Proc. Combust. Inst. 30 (2005) 875-882.

[19] J.H. Chen, E.R. Hawkes, R. Sankaran, S.D. Mason, H.G. Im, Direct numerical simulation of ignition front propagation in a constant volume with temperature inhomogeneities: I. fundamental analysis and diagnostics, Combust. Flame 145 (2006) 128-144.

[20] E.R. Hawkes, R. Sankaran, P. Pébay, J.H. Chen, Direct numerical simulation of ignition front propagation in a constant volume with temperature inhomogeneities: II. parametric study, Combust. Flame 145 (2006) 145-159.

[21] C.S. Yoo, T. Lu, J.H. Chen, C.K. Law, Direct numerical simulations of ignition of a lean n-heptane/air mixture with temperature inhomogeneities at constant volume: Parametric study, Combust. Flame 158 (2011) 1727-1741.

[22] C.S. Yoo, Z. Luo, T. Lu, H. Kim, J.H. Chen, A DNS study of ignition characteristics of a lean iso-octane/air mixture under HCCI and SACI conditions, Proc. Combust. Inst. 34 (2013) 2985-2993.

[23] M.B. Luong, Z. Luo, T. Lu, S.H. Chung C.S. Yoo, Direct numerical simulations of the ignition of lean primary reference fuel/air mixtures with temperature inhomogeneities, Combust. Flame 160 (2013) 2038-2047.

[24] R. Yu, X.-S. Bai, Direct numerical simulation of lean hydrogen/air auto-ignition in a constant volume enclosure, Combust. Flame 160 (2013) 1706-1716. 
[25] H. Zhang, E.R. Hawkes, J.H. Chen, S. Kook, A numerical study of the autoignition of dimethyl ether with temperature inhomogeneities, Proc. Combust. Inst. 34 (2013) 803-812.

[26] H.A. El-Asrag, Y. Ju, Direct numerical simulations of exhaust gas recirculation effect on multistage autoignition in the negative temperature combustion regime for stratified $\mathrm{HCCl}$ flow conditions by using $\mathrm{H} 2 \mathrm{o} 2$ addition, Combust. Theory Model. 17 (2013) 316-334.

[27] H.A. El-Asrag, Y. Ju, Direct numerical simulations of NOx effect on multistage autoignition of DME/air mixture in the negative temperature coefficient regime for stratified HCCI engine conditions, Combust. Flame 161 (2014) 256-269.

[28] S.O. Kim, M.B. Luong, J.H. Chen, C.S. Yoo, A DNS study of the ignition of lean PRF/air mixtures with temperature inhomogeneities under high pressure and intermediate temperature, Combust. Flame 162 (2015) 717-726.

[29] G. Bansal, H.G. Im, Autoignition and front propagation in low temperature combustion engine environments, Combust. Flame 158 (2011) 2105-2112.

[30] V. Mittal, D. Cook, H. Pitsch, An extended multi-regime flamelet model for IC engines, Combust. Flame 159 (2012) 2767-2776.

[31] A. Krisman, E.R. Hwakes, S. Kook, M. Sjöberg, J.E. Dec, On the potential of ethanol fuel stratification to extend the high load limit in stratified-charge compression-ignition engines, Fuel 99 (2012) 45-54.

[32] M. Talei, E.R. Hawkes, Ignition in compositionally and thermally stratified n-heptane/air mixtures: A direct numerical simulation study, Proc. Combust. Inst. 35 (2015) 3027-3035.

[33] M.B. Luong, T. Lu, S.H. Chung, C.S. Yoo, Direct numerical simulations of the ignition of a lean biodiesel/air mixture with temperature and composition inhomogeneities at high pressure and intermediate temperature, Combust. Flame 161 (2014) 2878-2889.

[34] M.B. Luong, G.H. Yu, T. Lu, S.H. Chung, C.S. Yoo, Direct numerical simulations of ignition of a lean n-heptane/air mixture with temperature and composition inhomogeneities relevant to HCCI and SCCI combustion, Combust. Flame 162 (2015) 4566-4585.

[35] M.B. Luong, G.H. Yu, S.H. Chung, C.S. Yoo, Ignition of a lean PRF/air mixture under RCCI/SCCI conditions: A comparative DNS study, Proc. Combust. Inst. 36 (2017) 3623-3631

[36] M.B. Luong, G.H. Yu, S.H. Chung, C.S. Yoo, Ignition of a lean PRF/air mixture under RCCI/SCCI conditions: Chemical aspects, Proc. Combust. Inst. 36 (2017) 3587-3596.

[37] A. Bhagatwala, T. Lu, J.H. Chen, Direct numerical simulations of HCCI/SACI with ethanol, Combust. Flame 161 (2014) 1826-1841.

[38] G. Bansal, A. Mascarenhas, J.H. Chen, Direct numerical simulations of autoignition in stratified dimethyl-ether (DME)/air turbulent mixtures, Combust. Flame 162 (2015) 688-702

[39] A. Bhagatwala, R. Sankaran, S. Kokjohn, J.H. Chen, Numerical investigation of spontaneous flame propagation under RCCI conditions, Combust. Flame 162 (2015) 3412-3426.

[40] F. Zhang, R. Yu, X.S. Bai, Effect of split fuel injection on heat release and pollutant emissions in partially premixed combustion of PRF70/air/EGR mixtures, Appl. Energy 149 (2015) 283-296.

[41] U. Egüz, N.C.J. Maes, C.a.J. Leermakers, L.M.T. Somers, L.P.H.D. Goey, Predicting auto-ignition characteristics of RCCI combustion using a multi-zone model, Int.J Automot. Technol. 14 (2013) 693-699.

[42] P. Domingo, L. Vervisch, Triple flames and partially premixed combustion in autoignition of non-premixed turbulent mixtures, Symp. (Int.) Combust. 26 (1996) 233-240

[43] F. Zhang, R. Yu, X.S. Bai, Direct numerical simulation of PRF70/air partially premixed combustion under IC engine conditions, Proc. Combust. Inst. 35 (2015) 2975-2982.

[44] J.B. Heywood, Internal combustion engine fundamentals, Mcgraw-Hill, New York, 1988.

[45] J.O. Hirschfelder, C.F. Curtiss, B.R. Bird, Molecular Theory of Gases and Liquids, Wiley, New York, 1965.

[46] J.H. Chen, A. Choudhary, B. de Supinski, M. DeVries, E.R. Hawkes, S. Klasky, W.K. Liao, K.L. Ma, J. Mellor-Crummey, N. Podhorszki, R. Sankaran, S. Shende, C.S. Yoo, Terascale direct numerical simulations of turbulent combustion using S3D, Comput. Sci. Discov. 2 (2009) 015001

[47] C.A. Kennedy, M.H. Carpenter, Several new numerical methods for compressible shear-layer simulations, Appl. Num. Math. 14 (1994) 397-433.

[48] C.A. Kennedy, M.H. Carpenter, R.M. Lewis, Low-storage, explicit Runge-Kutta schemes for the compressible Navier-Stokes equations, Appl. Num. Math. 35 (2000) 117-219.

[49] R.J. Kee, F.M. Rupley, E. Meeks, J.A. Miller, CHEMKIN-III: A FORTRAN chemical kinetics package for the analysis of gas-phase chemical and plasma kinetics, Technical Report SAND96-8216, Sandia National Laboratories, 1996.
[50] R.J. Kee, G. Dixon-Lewis, J. Warnatz, M.E. Coltrin, J.A. Miller, A Fortran computer code package for the evaluation of gas-phase multicomponent transport properties, Technical Report, SAND86-8246, Sandia National Laboratories, 1986.

[51] H.J. Curran, P. Gaffuri, W.J. Pitz, C.K. Westbrook, A comprehensive modeling study of n-heptane oxidation, Combust. Flame 114 (1998) 149-177.

[52] H.J. Curran, P. Gaffuri, W.J. Pitz, C.K. Westbrook, A comprehensive modeling study of iso-octane oxidation, Combust. Flame 129 (2002) 253-280.

[53] T. Lu, C.K. Law, C.S. Yoo, J.H. Chen, Dynamic stiffness removal for direct numerical simulations, Combust. Flame 156 (2009) 1542-1551.

[54] S. Tanaka, F. Ayala, J.C. Keck, A reduced chemical kinetic model for HCCI combustion of primary reference fuels in a rapid compression machine, Combust. Flame 133 (4) (2003) 467-481.

[55] Y. Ra, R.D. Reitz, A reduced chemical kinetic model for IC engine combustion simulations with primary reference fuels, Combust. Flame 155 (4) (2008) 713-738.

[56] H. Wang, M. Yao, R.D. Reitz, Development of a reduced primary reference fuel mechanism for internal combustion engine combustion simulations, Energy Fuels 27 (12) (2013) 7843-7853.

[57] C.S. Yoo, H.G. Im, Characteristic boundary conditions for simulations of compressible reacting flows with multi-dimensional, viscous and reaction effects, Combust. Theory Model. 11 (2007a) 259-286.

[58] C.S. Yoo, H.G. Im, Transient soot dynamics in turbulent nonpremixed ethylene-air counterflow flames, Proc. Combust. Inst. 31 (2007b) 701-708.

[59] C.S. Yoo, R. Sankaran, J.H. Chen, Three-dimensional direct numerical simulation of a turbulent lifted hydrogen jet flame in heated coflow: Flame stabilization and structure, J. Fluid Mech. 640 (2009) 453-481.

[60] C.S. Yoo, E.S. Richardson, R. Sankaran, J.H. Chen, A DNS study of a turbulent lifted ethylene jet flame in highly-heated coflow, Proc. Combust. Inst. 33 (2011) $1619-1627$.

[61] T. Passot, A. Pouquet, Numerical simulation of compressible homogeneous flows in the turbulent regime, J. Fluid Mech. 118 (1987) 441-466.

[62] Y. Wang, C.J. Rutland, Effects of temperature and equivalence ratio on the ignition of n-heptane fuel spray in turbulent flow, Proc. Combust. Inst. 30 (2005) 893-900.

[63] S. Kokjohn, R. Reitz, D. Splitter, M. Musculus, Investigation of fuel reactivity stratification for controlling PCI heat-release rates using high-speed chemiluminescence imaging and fuel tracer fluorescence, SAE Paper 2012-010375SAE. (2012)

[64] S.L. Kokjohn, M.P.B. Musculus, R.D. Reitz, Evaluating temperature and fuel stratification for heat-release rate control in a reactivity-controlled compression-ignition engine using optical diagnostics and chemical kinetics modeling, Combust. Flame 162 (2015) 2729-2742.

[65] W. Hwang, J.E. Dec, M. Sjöberg, Fuel stratification for low-load HCCI combustion: Performance \& fuel-PLIF measurements, SAE Transaction Paper 2007-014130, SAE 116(2007).

[66] J.E. Dec, W. Hwang, Characterizing the development of thermal stratification in an $\mathrm{HCCl}$ engine using planar-imaging thermometry, SAE Transaction Paper 2009-01-0650, SAE (2009).

[67] N. Peters, H. Pitsch, Solving combustion chemistry in engine simulations, in: T.K.D. Crolla, D.E. Foster, N. Vaughan (Eds.), Encyclopedia of Automotive Engineering, John Wiley \& Sons, Ltd (2014), pp. 1-9.

[68] J.E. Dec, W. Hwang, M. Sjöberg, An investigation of thermal stratification in HCCI engines using chemiluminescence imaging, SAE Transaction 2006-011518, SAE (2006).

[69] C. Westbrook, Chemical kinetics of hydrocarbon ignition in practical combustion system, Proc. Combust. Inst. 28 (2000) 1563-1577.

[70] W. Hwang, J.E. Dec, M. Sjöberg, Spectroscopic and chemical-kinetic analysis of the phases of HCCI autoignition and combustion for single- and two-stage ignition fuels, Combust. Flame 154 (2008) 387-409.

[71] J.E. Dec, Advanced compression-ignition combustion for high efficiency and ultra-low NOx and soot, in: T.K.D. Crolla, D.E. Foster, N. Vaughan (Eds.), Encyclopedia of Automotive Engineering, John Wiley \& Sons, Ltd (2014), pp. 1-40.

[72] R.E. Herold, J.M. Krasselt, D.E. Foster, J.B. Ghandhi, D.L. Reuss, P.M. Najt, Investigations into the effects of thermal and compositional stratification on $\mathrm{HCCI}$ combustion - part II: optical engine results, SAE paper 2009-01-1106, SAE, (2009).

[73] J. Krasselt, D. Foster, J. Ghandhi, R. Herold, D. Reuss, P. Najt, Investigations into the effects of thermal and compositional stratification on HCCI combustion part I: Metal engine results, SAE paper 2009-01-1105, SAE, (2009).

[74] F. Zhang, H.F. Liu, R. Yu, M. Yao, X.S. Bai, Direct numerical simulation of $\mathrm{H}_{2} /$ air combustion with composition stratification in a constant volume enclosure relevant to HCCI engines, Int. J. Hydrog. Energy 41 (2016) 13758-13770. 